\title{
OPERATION
}

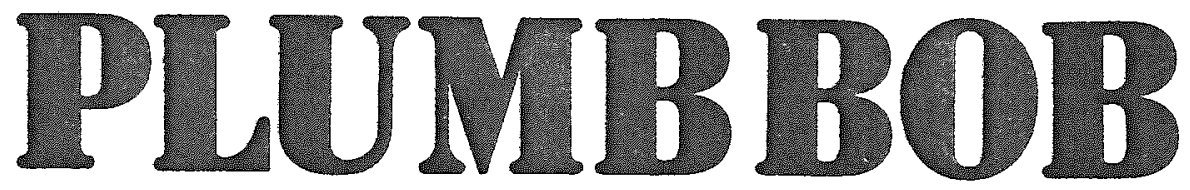

NEVADA TEST SITE

MAY-OCTOBER 1957

Project 26.3

\section{TEMPERATURES FROM UNDERGROUND DETONATION, SHOT RAINIER}

Issuance Date: January 16, 1959

\section{UNIVERSITY OF CALIFORNIA}

LAWRENCE RADIATION LABORATORY

LIVERMORE, CALIFORNIA 


\section{NOTICE}

This report is published in the interest of providing information which may prove of value to the reader in his study of effects data derived principally from nuclear weapons tests.

This document is based on information available at the time of preparation which may have subsequently been expanded and re-evaluated. Also, in preparing this report for publication, some classified material may have been removed. Users are cautioned to avoid interpretations and conclusions based on unknown or incomplete data.

PRINTED IN USA

Price $\$ 1.50$. Available from the Office of Technical Services, Department of Commerce. Washington 25, D. C. 


\section{DISCLAIMER}

This report was prepared as an account of work sponsored by an agency of the United States Government. Neither the United States Government nor any agency Thereof, nor any of their employees, makes any warranty, express or implied, or assumes any legal liability or responsibility for the accuracy, completeness, or usefulness of any information, apparatus, product, or process disclosed, or represents that its use would not infringe privately owned rights. Reference herein to any specific commercial product, process, or service by trade name, trademark, manufacturer, or otherwise does not necessarily constitute or imply its endorsement, recommendation, or favoring by the United States Government or any agency thereof. The views and opinions of authors expressed herein do not necessarily state or reflect those of the United States Government or any agency thereof. 


\section{DISCLAIMER}

Portions of this document may be illegible in electronic image products. Images are produced from the best available original document. 
Report to the Test Director

TEMPERATURES FROM UNDERGROUND DETONATION. SHOT RAINLER

By

T.C. Goodale, B. Ragent and A.H. Samuel

Broadview Research Corporation

Burlingarne. California

and

A.L. Anderson, D. E. Nielsen and J.L. Olsen

University of California Radiation Laboratory

Mercury, Nevada

July 1958 
$$
\text { . }
$$ 


\begin{abstract}
The results of temperature measuring experiments conducted for Rainier shot, Operation Plumbbob are described. The temperature distribution in the surrounding tuff resulting from the detonation of an underground nuclear device yielding 1. 7 kilotons of energy has been measured. Data indicate peak temperatures in the vicinity of $90^{\circ} \mathrm{C}$ existing in the central regions which drop rapidly to approach ambient temperatures at distances of about 180 feet from the original ground zero. Based on measurements taken in three holes drilled into the central regions, contours of constant temperature are constructed. The temperature picture is consistent with the consideration that most of the heat entered the water contained originally in the tuff and the unconsolidated material which filled the cavity after its initial collapse. The amount of energy contained in the central regions in the form of tuff heated to below $90^{\circ} \mathrm{C}$ is roughly estimated to be greater than one-half of the total energy release. An unsuccessful attempt to measure the temperature rise across the shock front of the pressure wave produced by the detonation is described, and reasons for failure are discussed.
\end{abstract}

\title{
ACKNOWLEDGMENTS
}

The members of the staff of Broadview Research Corporation who have contributed actively to this project are $R$. Clarke, $R$. I. Condit, T.C. Goodale, K. Kaplan, C.E. Noble, Jr., B. Ragent, A.H. Samuel, and J.V. Zaccor. Active participants on behalf of UCRI have been A. L. Anderson, D.E. Nielsen and J.L. Olsen. William Perrett and Joe Wistor of the Sandia Corporation cheerfully volunteered and cooperated in the use of recording equipment in the field. The entire program was ably coordinated by $\mathbb{R}_{0} G_{0}$ Preston, C. E. Violet, and D.T. Schuler, Jro, of UCRL. 


\section{CONTENTS}

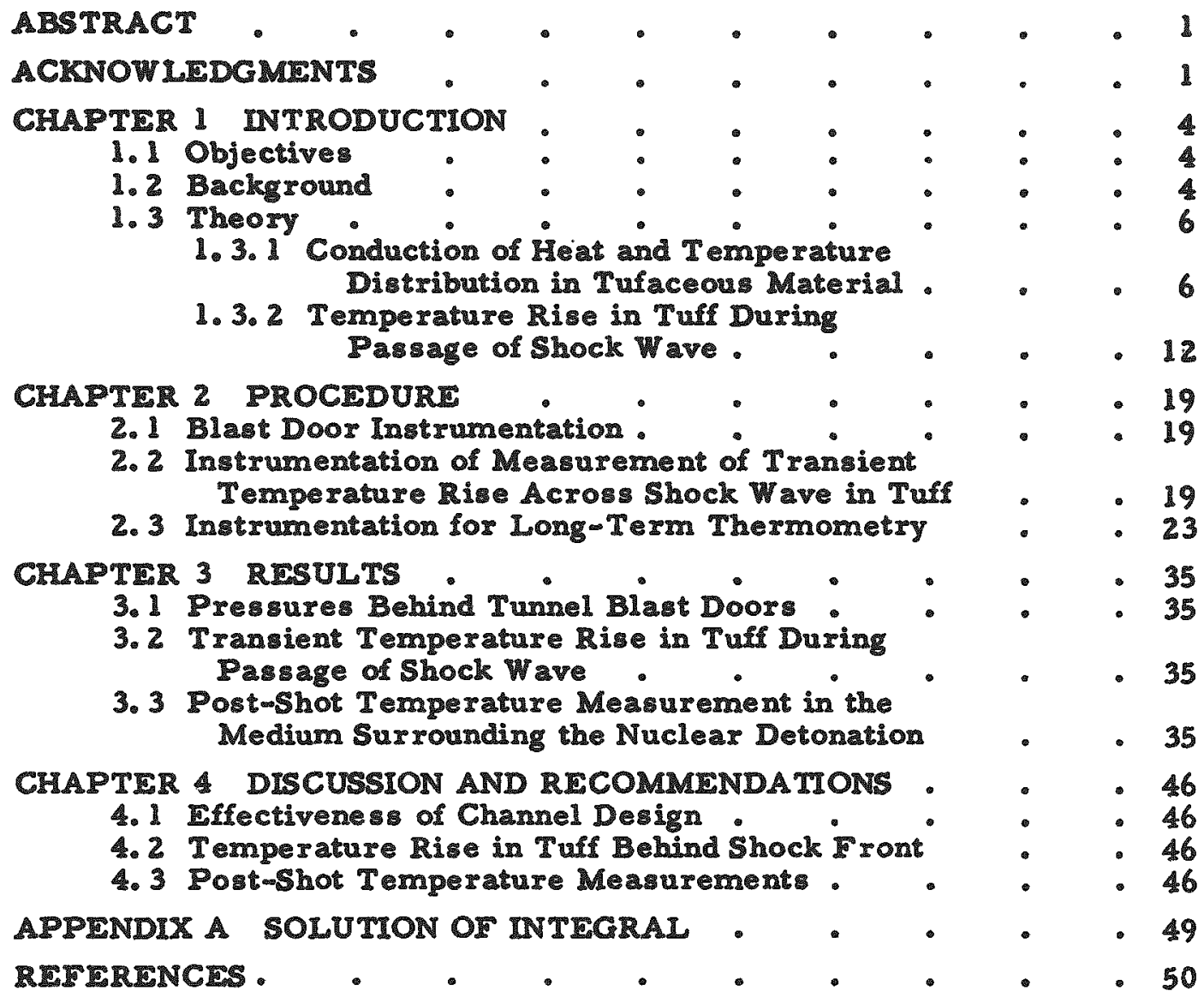

TABLES

1.1 Temperature Rise $\mathrm{v}$ - Instantaneous

Point Source.

1.2 $v_{\max }$ and $t_{\max }$-Instantaneous Point Source .

1.3 Temperature Rise $\vee-H o m o g e n e o u$ Spherical

Source •

1. Temperature Rise $v-S$ Constant Temperature

1.5 Temper ture Rise $v-$ Spherical Surface Source

1.6 Temperature Rise $v-$ Spherical Cavity Surface Source.

2.1 Comparison of Platinum Resistance The rmometer Calibrations

2. 2 Description of Logging Hole

4. 1 Calculation of Total Heat Content of Turf 


\section{CONTENTS (cont)}

\section{FIGURES}

1.1 Theoretical Temperature Distribution in Tuff at $r=1000 \mathrm{~cm}$. . .

1.2 Theoretical Temperature Distribution in Tuff at $t=3 \times 107 \mathrm{sec}$.

1. 3 Theoretical Temperature Distribution in

Turf at $t=10^{8} \mathrm{sec}$ Theoretical Estimate Shock Pressure vs
1. 4 Theor

1.5 Theoretical Estimate of Shock Temperature vs Radial Distance.

2. 1 Steps in Construction of Transient Temperature Probe . . . . . . . 28

2.2 Transient Temperature Probe $\quad: \quad \cdot \quad \cdot \quad \cdot \quad 29$

2.3 Platinum Resistance Thermometer Probe Unit . 30

2. 4 Profile of Rainier Tunnel Site and Diagnostic Holes . . . . . . . . 31

2.5 Plan and Elevation View of Diagnostic Holes $B, C$ and $D$. $\quad . \quad$. . . $\quad 32$

2.6 Plan View of Rainier Tunnel Site with Background Temperature Holes and Diagnostic Holes B, C and D

2. 7 Schematic Diagram of ac Resistance Bridge

3. 1 Typical Transient Temperature Probe Record

3. 2 Temperature Logs in B Hole

3. 3 Temperature Logs in C Hole

3.4 Temperature Logs in D Hole

3. 5 Isothermal Lines on the Surface Defined by

Diagnostic Holes $B_{s} C$ and $D$
3.6 Pre-Shot Temperature Log in UCRL Hole \#3
Made by USGS.

3. 7 Post-Shot Temperature $\log$ in the vertical Diagnostic Hole Made by USGS

3.8 Temperatures Recorded in the Rainier Tunnel 40-ft Background Temperature Holes. 


\section{CHAPTER I}

\section{INTRODUCTION}

\section{1 OBJECTIVES}

The objectives envisaged for this project were threefold in nature.

a. It was hoped that the temperature-time history of the tuff surpounding the shot cavity would be helpful in establishing a yield figure for the nuclear device tested.

b. Temperature measurements would be useful in documenting the gross effects of the nuclear explosion underground.

c. Suggestions had been made that the heat trapped in the ground might be useful for power production, mining or petroleum production, and so temperature distributions would be required for these feasibility studies.

Several additional developmental programs were undertaken. The first involved instrumenting the blast doors of the underground access tunnel with pressure indicators to determine post-shot pressure conditions in the sealed tunnel. The second involved the development and in stallation of rapidly responding temperature sensors to read the temperature rise across the shock front of the pressure wave generated by the detonation. These measurements would be useful in establishing the equation of state for the tuff and in evaluating the rate of energy loss in the medium as a function of distance from the blast.

The nature of the program changed several times during the course of its execution, but in general it was concerned with pressure and tem. perature measurement. It is therefore of interest to survey briefly the anticipated pressure and temperature effects.

\subsection{BACKGROUND}

The progran was undertaken as Project 26.3 of shot Rainier of Operation Plumbbob in 1957. The Rainier shot (Sept. 19, 1957) was an underground detonation yielding approximately 1.7 kilotons, set of $f$ in a chamber approximately $900 \mathrm{ft}$ below the surface of a mesa in the Nevada Proving Grounds. Access to the chamber was through a tunnel starting at the side of the mesa about 1700 ft from the chamber, containing several turns in the vicinity of the chamber.

As it appeared likely that this would be the first of a series of under ground shots, it was desired that the instrumentation be as complete as possible. At the same time, it was foraseen that difficulties might develop, and it was hoped that these would be overcome and not carry over to future underground shots. 
At the instant of firing of the shot, a large quanticy of energy is generated. Since the radiation is contained within the mesa, essentially the entire amount of energy is rapidly degraded to heat and mechanical energy. It was believed that a cavity, roughly spherical in shape, would be formed around the point of origin by vaporization, melting and compaction of the rock. Inside the cavity it was expected that a high temperature, in the neighborhood of the melting point of the rock, would initially prevail. A high pressure was also expected in the cavity due to presence of gases evolved from the rock at high temperatures. These might include occluded gases, rolatiles such as water, and other volatile materials produced in high-temperature chemical reactions. A shock wave was expected to propagate into the mesa, with consequent crushing and deformation of the rock structure. With increased distance from the originating point, this shock wave was expected to be transformed first into a plastic wave and finally into an elastic seismic wave. Transient increases in temperature and pressure were expected to accompany the wave especially in the shock region, with some permanent effects in all but the elastic regions.

The measurements initially proposed were:

Part 1: Measurement of pressure within the test chamber after the shot. Since one of the questions to be answered by this experiment was whether radioactivity would penetrate to the surface after the shot, and since an elevated pressure in the shot cavity would be the most obvious means of driving radioactive gas or fine particulate material to the surface, the measurement of pressure in the cavity was considered important. It was proposed to drill three very narrow vertical shafts into the region near the test chamber before the shot. While the interior portion of the holes might be eliminated by the explosion, it was expected that these holes would furnish a convenient means of inserting pressure probes into the cavity after the shot. It was also hoped that radiochemical sampling would be possible through these access holes.

Part 2: Measurement of temperature of the unaltered rock. Eight channels of temperature measurement were to be provided. Probes were to be inserted in bare holes before the shot. It was intended to measuxe the long-term temperature changes due to beat transfer before, and if possible, following the explosion.

Part 3: Measurement of temperature of the molten rock region. A similar system providing four channels of temperature measurement was proposed for measuring the temperature of the molten rock expected to be contained in the cavity. It was expected that the access holes mentioned in Part 1 might be used for the insertion of temperature sensing probes after the shot.

Better knowledge of the expected results of the shot, which became available soon after the starting date of April 24, 1957, caused a modification of the program.

The rocks composing the mesa in which the explosion was to take place consist of rhyolites and other volcanic tuffs, with measurable air space and water content. A preliminary shot, using 50 tons of high explosive, showed that the re would be a considerable degree of fracturing and dislocation of the rock in the vicinity of the explosion cavity. The 
original concept of the containment of the burst in a sealed cavity, with relative stability of other regions, had to be modified. It now seemed likely that the cavity would be in contact with fissures, and that any overpressure which might originally be present would very soon be relieved.

At the same time, calculations were started which were designed to estimate the extent of heat conduction through the rock. Even the first rough results showed clearly that measurable temperature increases due to conduction would be confined to distances of a few feet from heat sources for periods of months or even years. It therefore appeared that probes would have to be installed in the immediate vicinity of the test chamber, and (if installed before the shot) would probably not survive the explosion.

In view of these results the program of investigation was changed. Part 1 (pressure measurement) was greatly reduced in scope. Pressure measurement in the cavity was abandoned, and it was decided to confine pressure measurements to gauge installations at the blast doors of the tunnel. These gauges were to indicate pressures on the inside to observers on the outside of the blast doors.

Parts 2 and 3 (temperature measurement) were combined. All static temperature tests were to be made by means of probes inserted in holes which were to be drilled after the shot. At this stage it was intended that all holes would be drilled in a vertical direction from the top of the mesa. One hole was to penetrate the cavity, and temperatures in it were to be logged by a high-temperature probe. Other holes were to be drilled to predetermined points near the cavity, permanent probes were to be installed, and the change of temperature with time was to be measured.

In addition it was proposed that four to six probes be developed and installed which would measure the transient temperature rise in the rock due to the passage of the shock wave. These measurements were to be made at distances of 25 to $500 \mathrm{ft}$ directly above the test chamber. It was hoped that these measurements would help to define the behavior properties of the rock in the shock state. Because of the short time scale it was agreed that recording apparatus furnished by the Sandia Corporation would be utilized.

\section{3 THEORY}

\subsubsection{Conduction of Heat and Temperature Distribution in Tufaceous Material.}

The following calculations were carried out in order to determine the nature of the temperature distributions expected after the shot, and to help in planning the measurement program.

In addition, it was hoped that these calculations might be useful after the shot in attempting to determine the physical form and distribution of the energy deposited by the bomb in the tuff. These calculations would be useful also in normalizing the total heat enexgy present (giving an indication of the bomb yield) by comparison with the calculations for a specified hea source. The total energy present would be given by

$$
Q=\int 4 \pi \operatorname{Cd} v(r) x^{2} d x
$$


where $v(r)$ is the experimentally determined temperature distribution, $C$ is the specific heat of the rock, $d$ its density and $x$ is the radius. By comparing $v(r)$ at convenient $r$ with the calculations it was hoped that the experimental curves could give indications as to the physical configuration of hot material at very small radii.

It should perhaps be emphasized that all results in this section deal only with conduction of heat through a homogeneous rock. Experience indicates that additional methods of heat transfer may be operative, especially convection through fractures and fissures and the transfer of heat by means of vapors of volatile substances which may recondense in cooler regions. If this occurs these calculations, as presented below, are not representative of the true situation.

The calculations were all made from a single set of physical assumptions, based partially on the data regarding rock characteristics which were available at the time the calculations were performed. Subsequently better data have become available; however, these data do not alter the qualitative aspects of the results and it was not felt worthwhile to repeat the calculations using the newer data. The following assumptions were made:

(a) Heat energy liberated, $Q$, is $1.8 \times 10^{12} \mathrm{cal}$.

(b) Rock contains $9 \% \mathrm{H}_{2} \mathrm{O}$ and the heat required to raise it to $2000^{\circ} \mathrm{C}$ is $728 \mathrm{cal} / \mathrm{g}$. as $16 \%$.

(c) Density of rock, d, is taken as $1.89^{\prime} \mathrm{g} / \mathrm{cm}^{3}$. Air space taken

${ }^{\circ} \mathrm{C}^{-1} \mathrm{sec}^{-1}$.

(e) Heat capacity, C, taken as $0.330 \mathrm{cal} / \mathrm{g}{ }^{\circ} \mathrm{C}$.

(f) This gives for the diffusivity $S=K / C d$ the value $2.66 \times 10^{-3}$. For comparison we cite the following corresponding values for four other types of earth material:

\begin{tabular}{|c|c|c|c|c|}
\hline Material & $d$ & $\mathrm{C}$ & $\underline{K}$ & $\underline{S}$ \\
\hline "Average rock" & & & 4. $2 \times 10^{-3}$ & $11 . \overline{8 \times 10^{-3}}$ \\
\hline Brick & 2.6 & 0.20 & $2.0 \times 10^{-3}$ & $3.8 \times 10^{-3}$ \\
\hline Soil (average) & 2.5 & 0.2 & 2. $3 \times 10^{-3}$ & $4.6 \times 10^{-3}$ \\
\hline Soil (sandy, $8 \%$ moist) & 1.75 & 0.24 & $1.4 \times 10^{-3}$ & 3. $3 \times 10^{-3}$ \\
\hline
\end{tabular}

(It will be seen that the tufaceous rock of the mesa is presumed to be closer to brick or sandy soil than to average rock, because of its relatively open structure.)

(g) In some calculations it is assumed that a volume of rock has been melted and heated to $2000^{\circ} \mathrm{C}$ by the explosion, and that it fills a spherical cavity. Calculations based on the data given above yield $678 \mathrm{~cm}$ for a, the radius of such a cavity.

In all succeeding calculations quantity $\mathrm{v}$ will designate the temperature difference, $\left(T-T_{0}\right)(v=0$ before shot throughout mesa). For a homogeneous isotropic solid, such as we assume the mesa to be, the differential equation of heat conduction is

$$
\begin{aligned}
\frac{d v}{d t} & =S \nabla^{2} v \\
& -7-
\end{aligned}
$$


assuming that the diffusivity is constant over the time and temperature ranges under consideration, and we can investigate solutions corresponding to different boundary conditions.

1.3.1.1 Point Source. The simplest case to consider is that in which the entire quantity of heat is liberated instantaneously at a single point. In this case the equation is satisfied by:

$$
v=\frac{Q}{8 \mathrm{Cd}(\pi S t)^{3 / 2}} e^{-\left(r^{2} / 4 S t\right)}
$$

Putting in the assumed figures, this becomes

$$
v=4.72 \times 10^{14} t^{-3 / 2} \exp \left(-r^{2} / 0.01064 t\right)
$$

where time $t$ is in seconds and radius $r$ in centimeters. The values for $v$ obtained in this manner are given in Table 1.1.

It can be seen from the first line of Table 1.1 that at any given point the temperature rises to a maximum and then drops. The maximum temperature and the time of its occurrence can be calculated as follows:

$$
\begin{aligned}
v & =A t^{-3 / 2} \exp (-B / t): \\
A & =4.72 \times 10^{14} ; B=r^{2} / 0.01064 \\
\frac{d v}{d t} & =A e^{-B / t}\left(B t^{-7 / 2}-\frac{3}{2} t^{-5 / 2}\right)=0 \\
t_{\max } & =62.7 \mathrm{r}^{2} ; v_{\max }=2.125 \times 10^{11} \mathrm{r}^{-3}
\end{aligned}
$$

Values of $t_{\max }$ and $v_{\max }$ for given $r$ are given in Table 1.2.

Keeping in mind that one year is $3.16 \times 10^{7}$ seconds, we see that considerable times will elapse before any temperature rise can be detected at radial distances for which this approximation might be valid.

1.3.1.2 Homogeneous Spherical Source. In order to improve the calculation, we examine some other solutions which may give a better approximation to reality. One such calculation lets the heat be evolved instantaneously and homogeneously inside a spherical volume of radius a.

Carslaw and Jaeger give a partial solution for this case (Reference 1):

$$
v=\frac{V}{2 r(\pi S t)} \int_{0}^{a} x^{3} e^{-\left(r-x^{3}\right)^{2} / 4 S t} d x^{3}
$$

where $V$ is the initial temperature inside the sphere. This can be integrated, and making the substitution $\mathrm{V}=3 \mathrm{Q} / 4 \mathrm{ma}^{3} \mathrm{Cd}$, we obtain:

$v=\frac{3 Q}{8 \sqrt{\pi} r a^{3} C d}\left\{2 \sqrt{S t}\left[e^{-(x+a)^{2} / 4 S t}=e^{-(x-a)^{2} / 4 S t}\right]+r \sqrt{\pi}\left(e x f \frac{r+a}{2 \sqrt{S t}}-\operatorname{erf} \frac{r-a}{2 \sqrt{5 t}}\right)\right\}$

The solution of the integral is recorded in Appendix A.

In the calculation the same constants as before are used, with the addition of $\mathrm{a}=678 \mathrm{~cm}$. The results are given in Table 1.3 .

Since $a=678 \mathrm{~cm}$, values for $x=500 \mathrm{~cm}$ are omitted as falling inside the shell, where latent heats of fusion complicate the picture. It will be 
TABLE 1.1 TEMPERATURE RISE $\vee$ IN ${ }^{\circ} \mathrm{C}$ - INSTANTANEOUS POINT SOURCE

\begin{tabular}{rlllllll}
\hline$x_{0} \mathrm{~cm}$ & $1 \times 10^{6}$ & $5 \times 10^{6}$ & $1 \times 10^{7}$ & $2 \times 10^{7}$ & $3 \times 10^{7}$ & $1 \times 10^{8}$ \\
\hline 500 & $2.95 \times 10^{-5}$ & 38.4 & 1424 & 1630 & 1313 & 373 \\
1000 & $7.17 \times 10^{-36}$ & $2.90 \times 10^{-4}$ & 1.24 & 48.0 & 125 & 184 \\
1500 & $6.84 \times 10^{-87}$ & $1.81 \times 10^{-14}$ & $9.78 \times 10^{-6}$ & .135 & 2.49 & 57.0 \\
2000 & $<10^{-100}$ & $9.37 \times 10^{-29}$ & $7.04 \times 10^{-13}$ & $3.62 \times 10^{-5}$ & 0.0104 & 11.0 \\
2500 & $<10^{-100}$ & $4.02 \times 10^{-47}$ & $4.71 \times 10^{-22}$ & $9.27 \times 10^{-10}$ & $9.01 \times 10^{-6}$ & 1.33 \\
3000 & $<10^{-100}$ & $1.43 \times 10^{-69}$ & $2.75 \times 10^{-33}$ & $2.26 \times 10^{-15}$ & $1.63 \times 10^{-9}$ & 0.100 \\
\hline
\end{tabular}

TABLE $1.2 v_{\max }$ and $t_{\max }$-INSTANTANEOUS POINT SOURCE

\begin{tabular}{|c|c|c|c|c|c|}
\hline$r, \mathrm{~cm}$ & $t_{\text {max }} \mathrm{sec}$ & $v_{\max }{ }^{\circ} \mathrm{C}$ & $r, \mathrm{~cm}$ & $\mathrm{max}^{\mathrm{t}} \mathrm{sec}$ & $v_{\max }{ }^{\circ} \mathrm{C}$ \\
\hline $\begin{array}{l}500 \\
600 \\
700 \\
800\end{array}$ & $\begin{array}{l}1.57 \times 10^{7} \\
2.26 \times 11 \\
3.08 \times 11 \\
4.02 \times " 11\end{array}$ & $\begin{array}{r}1700 \\
984 \\
618 \\
414\end{array}$ & $\begin{array}{l}3000 \\
3300 \\
3600 \\
3900\end{array}$ & $\begin{array}{l}5.64 \times 10^{8} \\
6.83 \times 11 \\
8.13 \times 11 \\
9.54 \times 11\end{array}$ & $\begin{array}{l}7.87 \\
5.91 \\
4.55 \\
3.58\end{array}$ \\
\hline $\begin{array}{l}1000 \\
1200 \\
1400\end{array}$ & $\begin{array}{l}5.08 \times 11 \\
6.27 \times{ }^{11} \\
9.03 \times 13 \\
1.23 \times 10^{8}\end{array}$ & $\begin{array}{l}212 \\
123 \\
77\end{array}$ & $\begin{array}{l}4200 \\
4500 \\
4800\end{array}$ & $\begin{array}{l}\text { 1. } 11 \times 10^{9} \\
1.27 \times 11 \\
1.44 \times 11\end{array}$ & $\begin{array}{l}2.87 \\
2.33 \\
1.92\end{array}$ \\
\hline $\begin{array}{l}1400 \\
1600 \\
1800\end{array}$ & $\begin{array}{l}1.23 \times 10^{\circ} \\
1.61 \times n " 11 \\
2.03 \times n\end{array}$ & $\begin{array}{l}77.4 \\
51.9 \\
36.4\end{array}$ & $\begin{array}{l}5100 \\
5400 \\
5700\end{array}$ & $\begin{array}{ll}1.63 \times & 11 \\
1.83 \times & 11 \\
2.04 \times & 11\end{array}$ & $\begin{array}{l}1.60 \\
1.35 \\
1.15\end{array}$ \\
\hline $\begin{array}{l}2000 \\
2200 \\
2400\end{array}$ & $\begin{array}{l}2.51 \times " 1 \\
3.03 \times \\
3.61 \times\end{array}$ & $\begin{array}{l}26.6 \\
20.0 \\
15.4\end{array}$ & $\begin{array}{l}6000 \\
6500\end{array}$ & $\begin{array}{l}2.26 \times 11 \\
2.65 \times\end{array}$ & $\begin{array}{l}0.984 \\
0.774\end{array}$ \\
\hline $\begin{array}{l}2600 \\
2800\end{array}$ & $\begin{array}{l}4.23 \times \\
4.92 \times\end{array}$ & $\begin{array}{l}12.1 \\
9.68\end{array}$ & 7000 & $3.08 \times 11$ & 0.618 \\
\hline
\end{tabular}

TABLE 1.3 TEMPERATURE RISE $\vee$ IN ${ }^{\circ} \mathrm{C}-$ HOMOGENEOUS SPHERE SOURCE

\begin{tabular}{cccccccc}
\hline$x_{3} \mathrm{~cm}$ & $1 \times 10^{6}$ & $5 \times 10^{6}$ & $1 \times 10^{7}$ & $2 \times 10^{7}$ & $3 \times 10^{7}$ & $1 \times 10^{8}$ \\
\hline 1000 & 0.008 & 33.0 & 103 & 185 & 210 & 167 \\
1500 & $<10^{-3}$ & $<10^{-3}$ & $<10^{-3}$ & 4.94 & 15.5 & 61.7 \\
2000 & $<10^{-3}$ & $<10^{-3}$ & $<10^{-3}$ & $<10^{-3}$ & 0.300 & 15.2 \\
2500 & $<10^{-3}$ & $<10^{-3}$ & $<10^{-3}$ & $<10^{-3}$ & 0.007 & 2.70 \\
3000 & $<10^{-3}$ & $<10^{-3}$ & $<10^{-3}$ & $<10^{-3}$ & $<10^{-3}$ & 0.253 \\
\hline
\end{tabular}


seen that for large values of $r$ and $t$ the results tend to approach those in the previous table. Because of limitations in the available tabulations of the erf function, no values of $\mathrm{v}$ under $0.001^{\circ} \mathrm{C}$ are given.

1.3.1.3 Spherical Cavity Surface of Constant Temperature. Another possible approximation is given by assuming that heat proceeds from the surface of a sphere of radius a into an otherwise unbounded homogeneous region, the surface of the sphere being kept at a constant temperature $V$. For this, the temperature rise at any time $t$ and radius $r(\geq a)$ is given by

$$
v=\frac{a V}{r} \operatorname{erfc} \frac{r-a}{2 \sqrt{s t}}
$$

The use of this approximation implies a supply of heat to the surface of the cavity: e.g., by freezing of molten rock.

We use the same constants as before, letting $\mathrm{V}=2000^{\circ} \mathrm{C}$, and we obtain results which are given in Table 1.4.

As might be expected, this approximation gives no maximum $\mathrm{v}$ at any $r$. Because of the implied continuous generation of heat, this equation would not be expected to be valid at large values of $r$ and $t$. However, it might be the best approximation for small values of $t$ and $(r-a)$, if our phys ical assumptions are valid or if better ones can be found.

TABLE 1.4 TEMPERATURE RISE $\vee$ IN ${ }^{\circ} \mathrm{C}$ - SPHERICAL SURFACE AT CONSTANT TEMPERATURE

\begin{tabular}{lllllll}
\hline$r_{8} \mathrm{~cm}$ & $1 \times 10^{6}$ & $5 \times 10^{6}$ & $1 \times 10^{7}$ & $2 \times 10^{7}$ & $3 \times 10^{7}$ & $1 \times 10^{8}$ \\
\hline 1000 & 0.014 & 65.6 & 221 & 439 & 570 & 894 \\
1500 & $<10^{-3}$ & $<10^{-3}$ & $<10^{-3}$ & 10.6 & 35.8 & 235 \\
2000 & $<10^{-3}$ & $<10^{-3}$ & $<10^{-3}$ & $<10^{-3}$ & 0.637 & 47.4 \\
2500 & $<10^{-3}$ & $<10^{-3}$ & $<10^{-3}$ & $<10^{-3}$ & 0.005 & 6.89 \\
3000 & $<10^{-3}$ & $<10^{-3}$ & $<10^{-3}$ & $<10^{-3}$ & $<10^{-3}$ & 0.655 \\
\hline
\end{tabular}

1.3.1. 4 Heat Generation at the Spherical Surface. Yet another approximation can be made if we assume that the heat is generated instantaneously at the surface of a spherical shell of radius $a$, surrounded inside and outside by homogeneous rock. For this approximation we have the equation

$$
V=\frac{Q}{8 \pi r a C d(\pi S t))^{1 / 2}}\left[e^{-(x-a)^{2} / 4 S t}-e^{-(r+a)^{2} / 4 S t}\right]
$$

Making the same assumptions as before, we obtain temperature rises from this equation which are shown in Table 1.5. Since the error function does not occur here, small values of $\mathrm{v}$ can be more easily tabulated. 
TABLE 1.5 TEMPERATURE RISE $\vee$ IN ${ }^{\circ} \mathrm{C}-$ SPHERICAL SURFACE SOURCE

\begin{tabular}{lllllll}
\hline$r_{1} \mathrm{~cm}$ & $1 \times 10^{6}$ & $5 \times 10^{6}$ & $1 \times 10^{7}$ & $2 \times 10^{7}$ & $3 \times 10^{7}$ & $1 \times 10^{8}$ \\
\hline 1000 & 0.109 & 118 & 221 & 249 & 244 & 155 \\
1500 & $3.3 \times 10^{-25}$ & $1.68 \times 10^{-3}$ & 0.682 & 18.5 & 27.2 & 64.0 \\
2000 & $4.3 \times 10^{-69}$ & $2.2 \times 10^{-12}$ & $2.15 \times 10^{-5}$ & 0.0562 & 0.709 & 17.8 \\
2500 & $<10^{-100}$ & $2.0 \times 10^{-25}$ & $6.6 \times 10^{-12}$ & $2.78 \times 10^{-5}$ & $4.12 \times 10^{-3}$ & 3.27 \\
3000 & $<10^{-100}$ & $2.7 \times 10^{-42}$ & $1.9 \times 10^{-20}$ & $1.4 \times 10^{-9}$ & $5.2 \times 10^{-6}$ & 0.389
\end{tabular}

1.3.1.5 Instantaneous Source at the Surface of a Spherical Cavity. final approximation is the one given in Reference 1, page 305. Here we again have an instaneous spherical surface source at $r \equiv a_{3}$ but we also assume zero heat flux across the boundary $\mathbf{r}=a$. This might be considered equivalent to an empty cavity whose walls are heated by radiation. For this we write the formula:

$v=\frac{Q}{4 \pi \operatorname{raK}}\left\{\left(\frac{S}{\pi t}\right)^{1 / 2} e^{-(r-a)^{2} / 4 S t}-\frac{S}{a} \exp \left[\frac{r-a}{a}+\frac{S t}{a^{2}}\right] \operatorname{erfc}\left(\frac{r-a}{2 \sqrt{S t}}+\frac{\sqrt{S t}}{a}\right)\right\}$

Using the same assumptions as before, this yields the results for $v$ given in Table 1.6. Plots of results obtained from the se and the previous approximations are given in Figs. 1.1, 1.2 and 1.3, and show a general correspondence in trend.

TABLE 1.6 TEMPERATURE RISE $\vee$ IN ${ }^{\circ} \mathrm{C}-$ SPHERICAL CAVITY SURFACE SOURCE

\begin{tabular}{|c|c|c|c|c|c|c|}
\hline $\mathrm{r}_{\mathrm{g}} \mathrm{cm}^{\mathrm{t}}$ & $1 \times 10^{6}$ & $5 \times 10^{6}$ & $1 \times 10^{7}$ & $2 \times 10^{7}$ & $3 \times 10^{7}$ & $1 \times 10^{8}$ \\
\hline 1000 & 0.211 & 206 & 363 & 360 & 325 & 147 \\
\hline 1500 & $<10^{-3}$ & $<10^{-3}$ & 1.23 & 19.2 & 42.5 & 73.9 \\
\hline 2000 & $<10^{-3}$ & $<10^{-3}$ & $<10^{-3}$ & 0.099 & 1.20 & 23.2 \\
\hline 2500 & $<10^{-3}$ & $<10^{-3}$ & $<10^{-3}$ & $<10^{-3}$ & $<10^{-3}$ & 4.55 \\
\hline 3000 & $<10^{-3}$ & $<10^{-3}$ & $<10^{-3}$ & $<10^{-3}$ & $<10^{-3}$ & 0.58 \\
\hline
\end{tabular}




\section{32 TEMPERATURE RISE IN TUFF DURING PASSAGE OF SHOCK WAVE}

Calculations of the expected temperature rise in tuff may be made in those regions in which a shock wave will be supported. These calculations as reported here follow the work of previous investigators (Reference 3).

We as sume that the tuff can be represented by an idealized mixture of incompressible solid and ir, and an ideal gas. Let $\xi=P_{\mathrm{s}} / \mathrm{P}_{\mathrm{o}}=$ pressure ratio at the shock front, $T=$ temperature, $P=$ density, and $P=$ pressure. Subscripts $o, f$, and s refer to initial, final, and shock conditions, respecm tively.

The Rankine-Hugoniot adiabat yields, for an ideal gas

$$
\frac{T}{T_{0}}=\frac{P_{P_{0}}}{P_{0}^{P}}=\frac{\xi(\xi+6)}{6 \xi+1}
$$

Let $m_{2}$ be the mass per unit volume of air and $m_{1}$ be the mass per unit volume of the solid. Then the increase in heat content of the air is

$$
Q_{\text {air }}=m_{2} h_{2}\left(T-T_{0}\right)=m_{2} h_{2} \frac{\left(\xi^{2}-1\right)}{6 \xi+1} \text {. }
$$

where $h_{2}$ is the specific heat of the air.

Assuming very rapid mixing of the air and incompressible solid so that equilibrium heat transfer occurs, the total heat content increase for the mixture just equals that for the air so that

or

$$
Q_{\text {air }}=Q_{\text {mix }}
$$

$$
\left(m_{1} h_{1}+m_{2} h_{2}\right)\left(T_{1}-T_{0}\right)=m_{2} h_{2} \frac{\left(\xi^{2}-1\right)}{6 \xi+1}
$$

whence

$$
\frac{T_{f}}{T_{0}}=1+\frac{m_{2} h_{2}}{m_{1} h_{1}+m_{2} h_{2}} \frac{\left(\xi^{2}-1\right)}{6 \xi+1}
$$

Since for most cases $h_{1}=h_{2}$,

$$
\therefore \frac{T_{f}}{T_{0}}=1+\frac{m_{2}}{m_{1}+m_{2}} \frac{\left(\xi^{2}-1\right)}{6 \xi+1}
$$

Calculation of the temperature rise at any radius thus resolves itself to a determination of $\xi$, the pressure ratio as a function of radius.

Several methods are available for estimating the peak shock pressure at various radii from ground zero. The most straight-forward of these methods involves the direct machine integration of the hydrodynamic conservation equations forward in time for each radius. The difficulties inherent in such calculations are great and the question of initial conditions involving wave shapes is troublesome. Nevertheless, calculations have been made in this fashion for some media.

In addition, several approximate schemes have been developed for dealing with the propagation of shock waves in media. Some of these are the Penny-Das Gupta, Kirkwood-Bethe, Kirkwood-Brinkley (referred to in Reference 2), Poxzel (Reference 3), etc. schemes. One derived curve of pressure versus distance derived by UCRL is given in Fig. 1.4. Using this data the expected temperature rise as a function of distance is plotted in $F$ ig. 1.5. The data used in calculating these figures are: 


$$
\begin{aligned}
& P_{\text {solids }} \approx 2.6 \mathrm{~g} / \mathrm{cm}^{3} \\
& p_{\text {air }}=9.85 \times 10^{-4} \mathrm{~g} / \mathrm{cm}^{3} \text { at } 6600-\mathrm{ft} \text { alcitude } \\
& \text { s } \quad=\mathrm{P} / \mathrm{P}_{0^{\circ}} \text { where } \mathrm{P}_{\mathrm{O}}=594 \mathrm{~mm} \mathrm{Hg} \text { at this altitude } \\
& T_{0}=16.5^{\circ} \mathrm{C}
\end{aligned}
$$

Tuff is assumed to consist of $27 \%$ air and $73 \%$ incompressible solid. $m_{2}=2.66 \times 10^{-4} \mathrm{~g}$ (for air)

$m_{1}=1.9 \mathrm{~g}$ (for solid) 


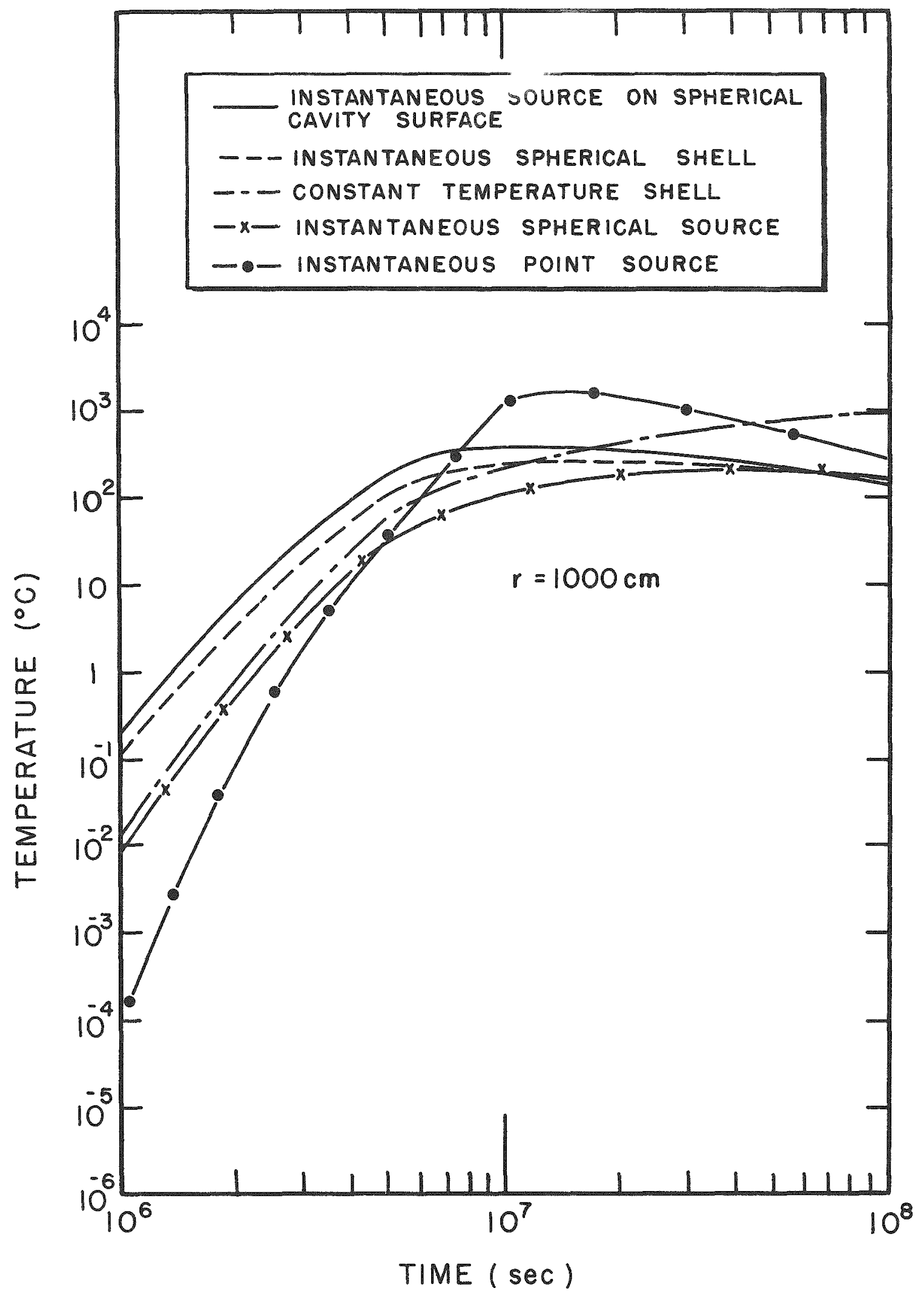

Figure 1.1 


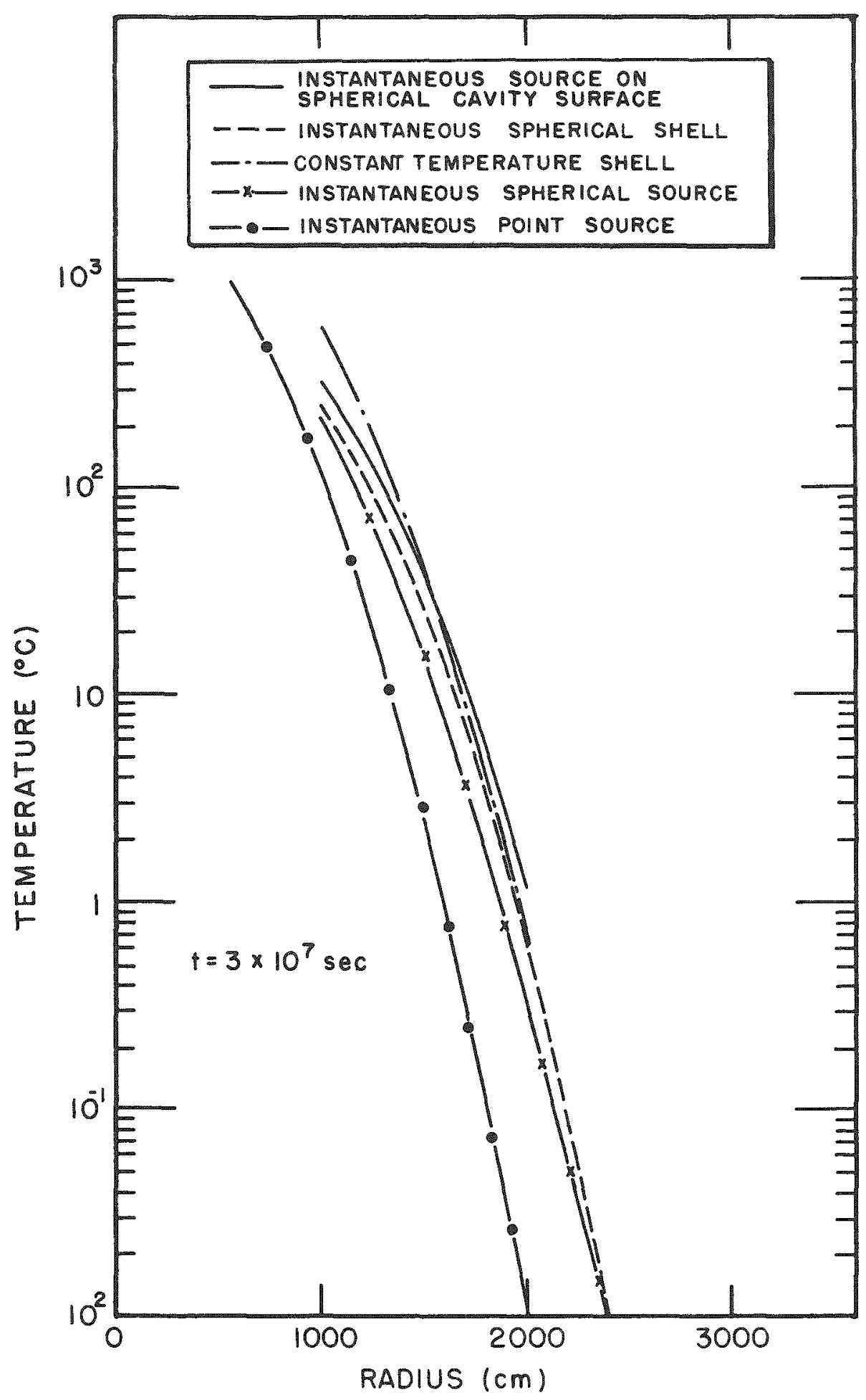

Figure 1.2 


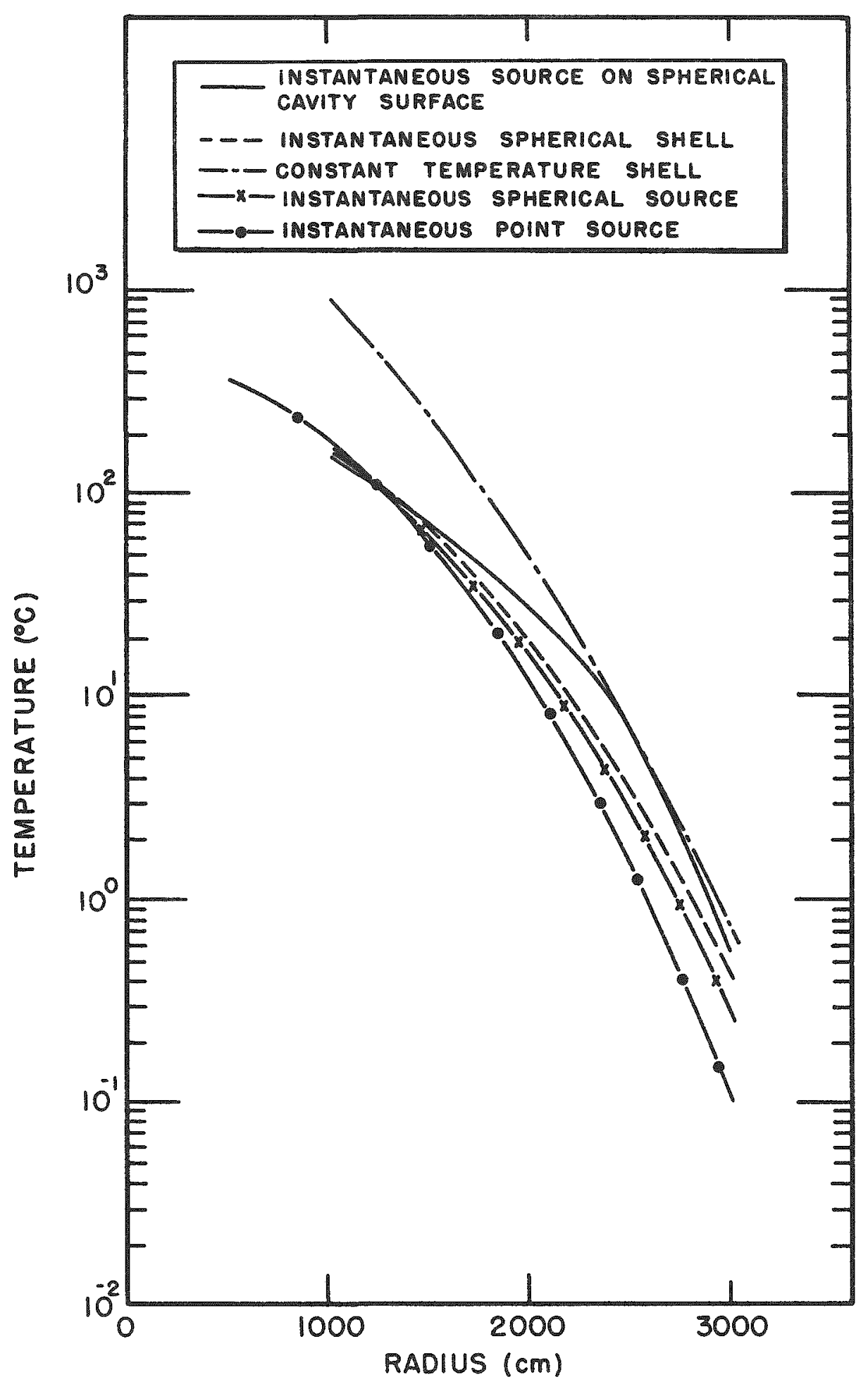

Figure 1.3 


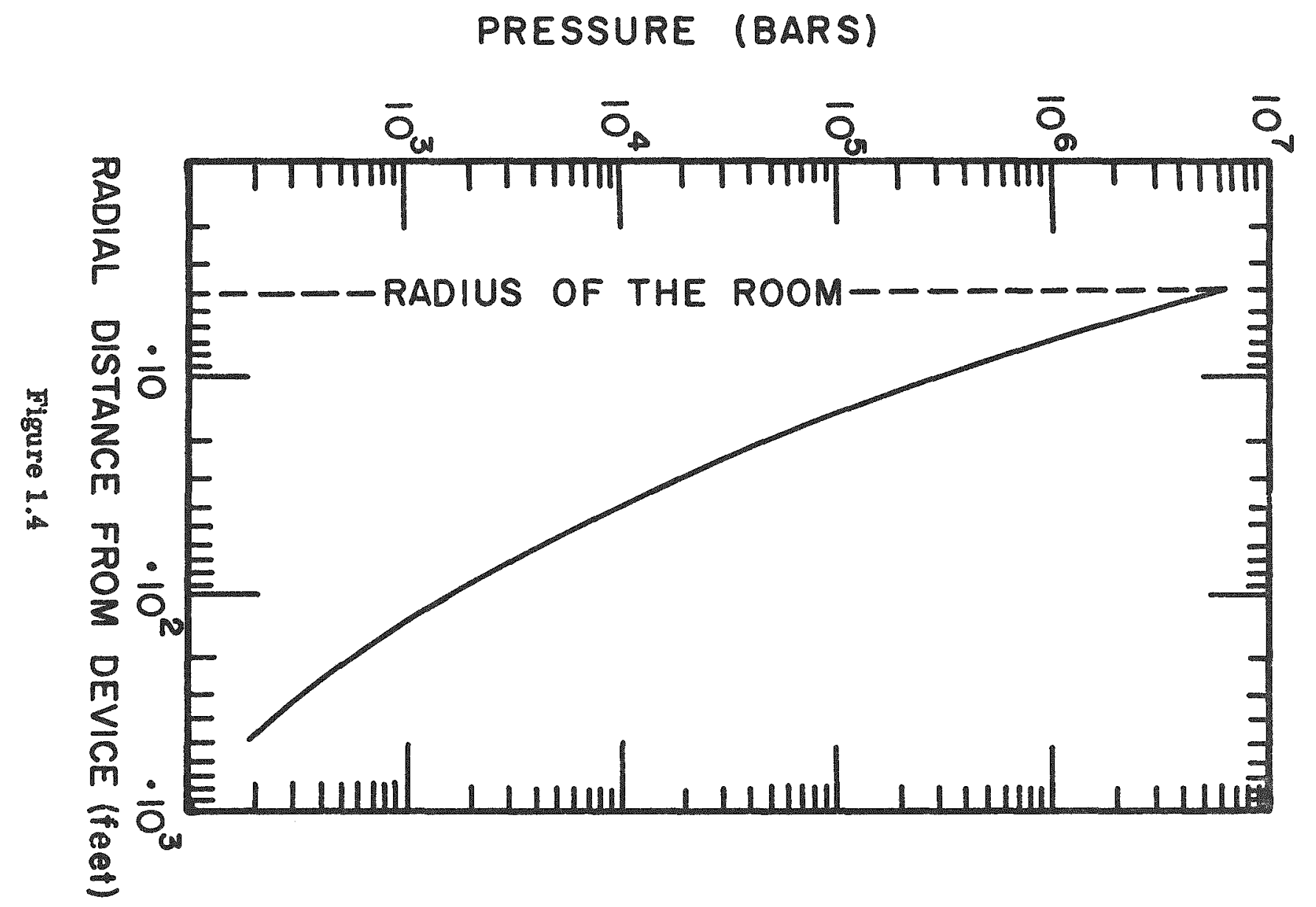




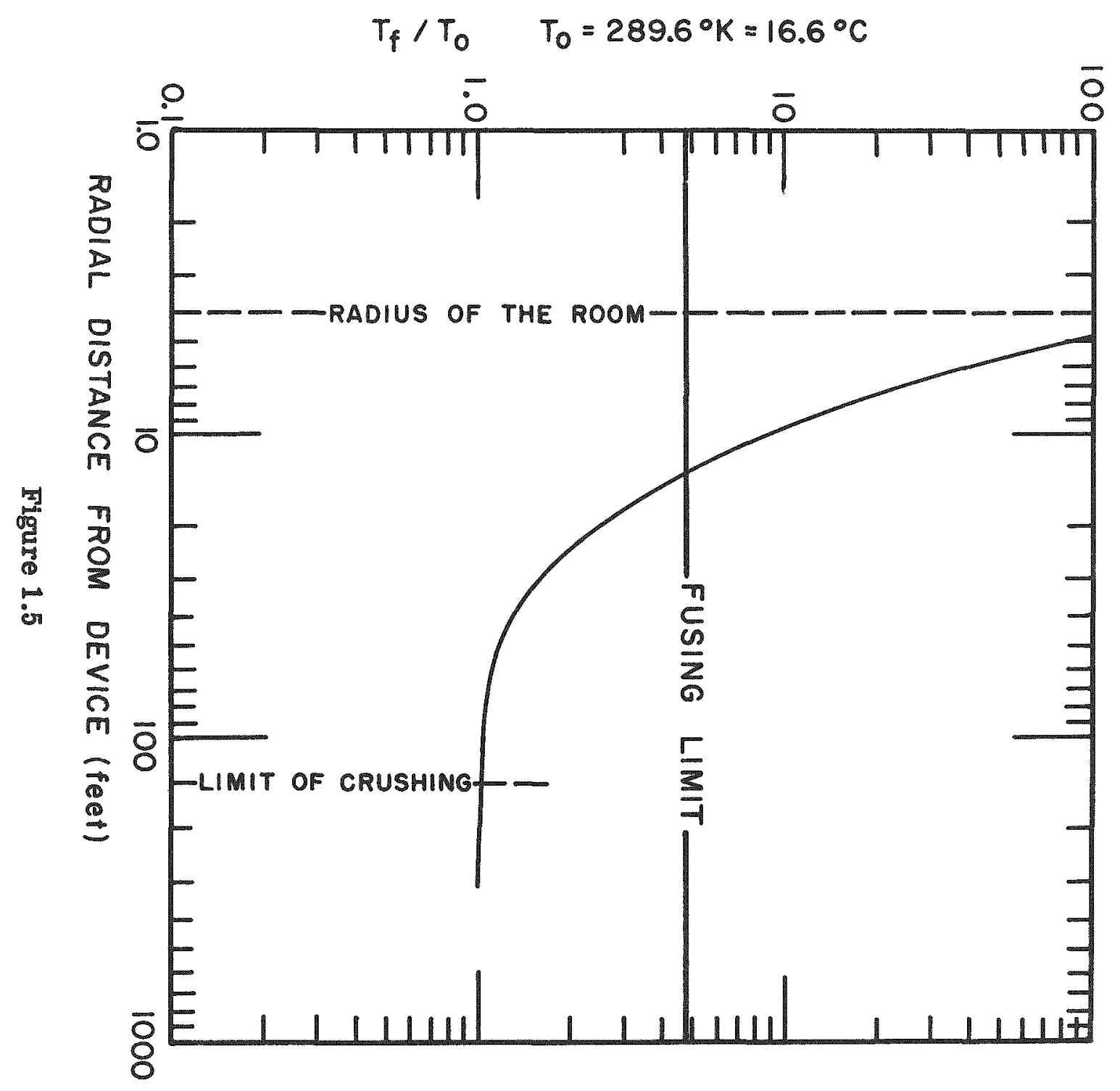




\section{CHAPTER 2}

\section{PROCEDURE}

The construction, calibration and field installation of equipment used to implement the three parts described in Section 1.2 are discussed in this chapter.

\subsection{BLAST DOOR INSTRUMENTATION}

The access tunnels to the site of the nuclear shot and to the sites of preliminary shots were closed by heavy blast doors set in concrete frames. It was desirable to ascertain after the shot the pressure and composition of the air or gas behind these blast doors, and Broadview Research Corporation undertook the task of providing instrumentation for this purpose.

The technique used here consisted of pipes running through the concrete frames of the blast doors and connected to the gage stations with copper tubing. The assembly started with one-inch iron pipe sections, three feet long, which were inserted in holes drilled through the blast doors and then grouted in. These were connected by standard pipe couplings to $3 / 8$ inch (nominal) type-K soft-copper water tubing $10.500-i n .0 . d_{0}, 0.049-i n$. wall thickness). This ran to the gage stations, passing through any additional blast doors by means of one-quarter-inch iron pipe, threaded at both ends and coupled to the copper tubing. Three kinds of gage stations were used. The first type (No. 1) consisted of a copper tubing cross inserted into the copper tubing as sembly.

Two openings contained, respectively, (a) a needle valve to the tunnel and (b) a needle valve and pressure gage. One of these stations was inserted in each line on the outside of each blast door. The second type (No.2) was installed at the tunnel exits and was identical with No. 1 except that a $T$ was used instead of a cross at the end of the line. The third type (No. 3) was a gas-and-dust sampling station. One of these stations was installed at the end of the one-inch pipe through the originating door at each assembly. It consisted of a gate valve and sampling head. Gate valves were chosen in order to provide a straight-line path to the sample head and to minimize settling out of dust.

Pressure gages were by Ashcroft, type 1379a. They had ranges of $0-160$ psig and were calibrated to $0.5 \%$ accuracy.

Three tunnels were instrumented in this manner by Broadview personnel. Tunnels $U-12-B$ and $U-12-D$ were instrumented in July, 1957, and tunnel U-12-C, in September, 1957. Two blast doors were instrumented in $\mathrm{U}-12-\mathrm{B}$, two in $\mathrm{U}-12-\mathrm{C}$ and one in $\mathrm{U}-12-\mathrm{D}$. Approximately $2,700 \mathrm{ft}$ of copper tubing, twelve pressure gages and the necessary auxiliary equipment (pipe, couplings, etc.) were used. The outer ends of the assemblies, those with the No. 2 terminators, were installed in rugged crypts near the tunnel entrances. After the systems were assembled, they were pressuremtested at $1000 \mathrm{psi}$ with the gage valves closed, and all leaks were eliminated. A final test, including the gages, was run at $150 \mathrm{psi}$, and the equipment was left in place with the gage valves shut.

\section{2 INSTRUMENTATION FOR MEASUREMENT OF TRANSIENT TEMPERA- TURE RISE ACROSS SHOCK WAVE IN TUFF}

The requirements which must be fulfilled by a sensor capable of reproducing the transient temperature rise across a shock wave are: 
1. Very rapid response $\left(10^{-5}\right.$ to $10^{-7}$ seconds).

2. Electrical output signal for remote recording.

3. Intimate coupling to sampled medium.

4. Insensitivity to stimuli other than temperature.

Initially, it might seem that either a thermocouple or a resistance thermometer might be appropriate for the designated purpose. However, it was soon seen that conventional thermocouples could not give a sufficiently rapid response. In conventional thermocouples there is a welded bead or other high-mass irregularity at the metal junction. Thin-sheet thermocouples have been plated onto metallic bases, but this method was not applicable in this case. It was therefore decided to develop a resistance thermometer which had to be small in order to allow rapid heating. It also had to be grouted into the rock in order to couple with the rock well enough to make sure that the temperature rise measured would be that of the rock and not of the thermometer. This immediately raises a problem. Without a grouting or binding material, contact with the rock cannot be adequate; but if such a material interposes between the thermometer and the rock, its own temperature will be the one recorded. It was thus necessary to choose a grouting material which was similar in its properties to the rock. The material selected was a product of U.S. Cypsum Company, Hydro-Stone, which is similar to plaster of Paris in appearance and properties. The density and fraction of air space of Hydro-Stone aggregates averaged around 1.70 and 0.25 , respectively. All measurements of transient temperature therefore relate to an environment of Hydro-Stone.

The resistance of metals also changes as a result of strain, and it was important to choose a thermometer design for which this effect would be small. This implies a high change in resistance with temperature. Suitable metals are platinum, copper, and gold having temperature coefficients of resistivity of $3-4 \times 10^{-3} \cdot \mathrm{C}-1$.

Three approaches to this problem were tried. They were:

1. "Platinum-bright" strips.

2. Platinum or copper wire.

3. Gold foil.

Liquid bright platinum is a product of Hanovia Company of Newark, N.J., and consists of a suspension or solution of platinum salts in an organic vehicle. Upon heating, this material is reduced to platinum. When applied to glass or other smooth surfaces, platinum is obtained as a smooth coherent layer. Such layers have been successfully used as transient resistance the mometers by Rabinowicz. Jessey, and Bartsch of the Guggenheim Aeronautical Laboratory of the California Institute of Technology, and by Dr. D. Bershader and his group at Lockheed Corporation. The attempt, here, was made to form suitable conducting layers of platinum on Hydro-stone surfaces. Smooth Hydro-Stone surfaces were obtained by casting on glass. Lines were then drawn on small $(0.8-1 \mathrm{~cm})$ shards of this material and the platinum was reduced by ignition at $600^{\circ} \mathrm{C}$. Pieces which gave suitable resistances (in the vicinity of $300 \mathrm{ohm}$ ) were selected and small drops of solder were applied to each end of the platinum line. With suitable care the se could be made to wet the platinum surface. Copper wires were then set into the solder beads. and the entire assembly was put into a mold which was filled with HydroStone. About eighty of these elements were prepared. Water-proofing with paraffin and with collodion proved insufficiently effective, but two coats of Epon 820 epoxy resin, mixed with Epon curing agent $U$ in $4: 1$ ratio, gave 
adequate protection from moisture. It was estimated that the thickness of the conducting platinum layer was $0.5-1 \mu$. Since this method gave excellent bonding to the Hydro-Stone and negligible thermometer lag, it was hoped that it could be adopted. Unfortunately, thermometers which were prepared by this method showed fluctuations in resistance; in some cases all conductivity was lost. The platinum layer had no tensile strength except that of the HydroStone substrata and it appeared that stresses in the Hydro-stone cause cracks (even long after casting) which could partially or totally sever the continuity of the platinum strip. This method was, the refore, eliminated from consideration.

Wire resistors were produced from 0.001 -in. platinum wire, obtained from Wildberg Brothers Smelting and Refinery Company of San Francisco, and from 0.002-in. General Electric copper magnet wire, covered with Formex insulation. The platinum wire resistors required 25 ft of wire and were wound on cylindrical $1 / 2$ in. $x$ 1/2 in. Hydro-stone cores, especially grooved to keep the wires from touching. Small dabs of Lix-Crax ceramic cement were used to keep the wire from unwinding. The copper resistors were wound on 1 in. $x 1-1 / 2$ in. cards. One-hundred feet of wire were required. The resistors in each case were set in molds and buried in cast Hydro-stone. Copper lead wires were soldered on (in the case of the copper wire).

The small-scale tests (described later) which were run on these thermometers showed large unexplained signals, which were attributed to induction effects. Non-inductively wound copper resistors showed some improvement. In the end, however, it was decided not to utilize these resistors because of their significantly greater mass and poorer bonding to the Hydrostone.

The gold leaf resistors which were finally selected were made from gold leaf manufactured by Witt Coe Manufacturing Company of Providence, R.I. This leaf came in sheets $3-3 / 8$ in. square. Sheets of gold leaf were placed on the wetted surface of Hydro-Stone slabs, $1 / 8$ in-thick, which had been previously cast against clean glass. The sheets of gold leaf were picked up by one edge, using a moistened enameled pencil to which the gold adhered to form a small flag. The free end of the leaf was brought in contact with the wet Hydro-Stone. Interfacial tension between the gold and the water then drew the gold leaf down to the wet surface of the Hydro-Stone. This procedure, performed in draft-free room, produced smooth gold films on the HydroStone after a small amount of practice. After the Hydro-Stone dried, the gold leaf adhered to it. These sheets of gold-coated Hydro-Stone were sawed into pieces $1 / 2$ in. square. The surfaces of the squares were scribed to produce the resistance elements. A piece of hypodermic tubing, 0.025-in. o.d. , was filed to produce a square end beveled on the inside to produce a sharpened edge. The tube was then bent into $a \mathrm{~V}$, and the unsharpened end held in a pin vise. When this small tubular chisel was drawn over the sur face of gold leaf on Hydro-Stone, it cut a smooth groove in the surface without appreciable tearing of the adjacent gold leaf. Equally spaced grooves were cut in the gold-filmed surface of the Hydro-stone in such a pattern that an extended electrical path was produced in the gold leaf. The spacing of the grooves was adjusted to produce a resistance of approximately $300 \mathrm{ohms}$ across the element. The 0.010-in. copper leads were cemented to the back of the element in such a way that their ends were adjacent to opposite ends of the gold leaf element. Connection to the gold leaf was made by conducting silver paint. The element leads were soldered to connecting cables and the assembly centered in a greased aluminum mold which was subsequently filled with Hydro-Stone to produce the probe. The probes were waterproofed with 
two coats of Epon 820 resin as above and were then copper plated to a thickness of approximately 0.005 in. This copper plating was designed to complete electrical shielding of the probe and was connected to the cable shield, which was used as a current lead. For further waterproofing, a plastic seal was cast over the cable end of the probe and the first $1-1 / 2$ in. of the cable. The plastic used was Scotchcast No. 4, and a $3 \mathrm{M}$ liquid rubber was used to bond the Scotchcast to the plastic cable covering. Molds were machined from Teflon bat stock; fairly large pouring holes were found neces sary. Figures 2.1 and 2.2 show the se probes in various stages of production.

In order to test the response of the transient temperature probes, scaled explosive tests were undertaken. The scaling was on the basis $W^{1 / 3} d=$ const, where $W$ is the TNT equivalent of the charge and $d$ is the distance from the center of the charge to the sensing element of the probe. The charges used were Composition A 110-gram spheres. Since these charges are about 2 in. in diameter, and d values ranged from 6 to $24 \mathrm{in.}$, it is evident that great precision is impossible; fortunately it was not necessary for the qualitative results desired. Experiments were carried out in Hydro-Stone and oil media. For the Hydro-Stone experiments, the probes were embedded in cylindrical Hydro-Stone blocks 9 to $15 \mathrm{in}$. in diameter depending on d. The probes were buried in at least 6 in. of Hydro-Stone, with leads coming through one flat surface of the cylinder, and the charge was set in a hemispherical cavity on the other flat surface. For the oil tests, the probes were put in a cavity in the Hydro-Stone block which was filled with lubricating oil. Charge and block were buried in sand. In most shots, control probes of nichrome wire were placed next to the test probe. Signals were obtained as oscilloscope traces and photographed.

Twenty-four shots were made. Results in general showed sharp pulses upon arrival of the stress wave, with rapid trailing off. There were, however, a number of unexplained spurious peaks, oscillations and signal failures. In some instances these could be explained by equipment failures, in others by mechanical failure of the probe, inductance or strain effects. The gold leaf probes showed fewer unexplained phenomena than others and were selected on this basis.

It should be emphasized that these tests were very imperfect reproductions of the actual shot conditions. In particulax, the sealing laws do not hold at such close distances to the charge, nor do they hold in media other than air. It is evident from Section 1.3 .2 that in order to obtain readable temperature rises we must be in the pressure range above $10^{3}$ bars, or in the case of conventional explosives very close to the charges indeed.

After the gold-leaf probe design was adopted, about forty of these probes were manufactured and calibrated using fixed temperature points. Twelve were sent to the Nevada Test Site for installation and six were installed at distances of 25 to $400 \mathrm{ft}$ from ground zero.

Records of the signals from the probes were taken on Sandia Coxporation equipment, six recording channels having been made available for these measurements through their courtesy. The recording equipment consisted of a Consolidated Engineering Company System-D bridge-and-amplifier system whose output was recorded on an Ampex tape recorder. The overall frequency response of this system is less than a thousand cycles per second, much too narrow for the desired temperature information, but the best which was available within the operational time scale. 


\section{3 INSTRUMENTATION FOR LONG-TERM THERMOMETRY}

\subsubsection{General}

The choice of an instrument for measuring long-term temperature changes in the mesa after the shot lies at first glance between the rmocouples and resistance thermometers. The thermocouple has several impressive advantages. Thermocouples are small, stable, wide-range instruments, with rapid response signals that are largely irdependent of the length and condition of the connections between the instruments and the recorder, and which can be measured on relatively simple instruments. However, they are essentially low-sensitivity instruments, and it was not anticipated that a precision of more than $0.1^{\circ} \mathrm{C}$ could be attained. Other less important considerations in using thermocouples were the necessity of maintaining a cold junction under field conditions and the difficulty of maneuvering with long lengths of thermocouple wire in narrow acces soles.

Resistance thermometers are based on the change of resistance of a conductor with temperature. Metals have small positive temperature coefficients of resistance while nonmetals (specifically semiconductors) have large negative temperature coefficients of resistance. Thus the semiconductor resistance thermometers (thermistors) are capable of giving very great precision. Unfortunately the accuracy of these instruments is not equally dependable, as a certain amount of drift in resistance values can sometimes be observed. It was found that no therristors were commercially available which could be depended upon to give reproducible results over many months under field conditions. A metal resistance thermometer was therefore chosen for long-term temperature measurements. Commercially available probes were made of copper or platinum. Since it was anticipated that some probes would be left in place for long periods of time, stability was a very important consideration. Platinum resistance thermometers were therefore selected. Platinum wire for thermometer use should pass two tests: (1) the ratio of the resistance at $100^{\circ} \mathrm{C}$ to that of $0^{\circ} \mathrm{C}$ should be 1.392 or greater, and (2) the wire should melt in a hot flame without sputtering, thus indicating homogeneity and absence of air inclusions. Platinum wire which passes these tests is used as the primary standard of temperature over a range from $-183^{\circ} \mathrm{C}$ to $+630^{\circ} \mathrm{C}$, which included the expected values of most of the temperatures to be measured, and platinum resistance the rmometers had been successfully used up to $1650^{\circ} \mathrm{C}$.

The planned measurements for this shot were as follows:

1. Measurement of rock temperatures at fairly large distances (1ateral) from the site of the explosion. Access was to be through holes drilled from top of mesa. Probes were to be left in the holes for several months.

2. Logging of vertical hole which was to penetrate into cavity. Many temperatures to be read in relatively short time.

This plan was made in the expectation that the explosion heat would largely be contained in a cavity with impervious walls, and that the main heat transfer mechanism would be conduction. In other words, the calculations outlined in Chapter 1 were expected to be fairly close to the actual case. It was therefore expected that temperature changes at distances of $50-100 \mathrm{ft}$ from gound zero would be quite small, and that temperature probes for the holes outside the cavity would need to have precision and accuracy of $10-2$. $10^{-3}{ }^{\circ} \mathrm{C}$. On the other hand, temperatures in the cavity might be over $1000^{\circ} \mathrm{C}$. and a rugged high temperature probe would be required for logging. 
The probes selected were platinum resistance thermometers. The resistance was 100 ohms at $0^{\circ} \mathrm{C}$. These were Weiller-type instruments, encased in stainless steel, produced by Glass-quar Company of New York and furnished by Hallikainen Instruments of Berkeley, California. Figure 2. 3 shows the detailed construction of these probes.

Twelve probes were originally ordered for measurements at temperatures up to $300^{\circ} \mathrm{C}$, one probe good for measurements up to $600^{\circ} \mathrm{C}$ and one high-temperature probe good for measurements to $1200^{\circ} \mathrm{C}$. However, the high temperature probe received was not satisfactory, and the high temperature probe used was assembled by Broadview Research Corporation personnel.

The measurement apparatus for resistance the mometers consisted essentially of a Wheatstone bridge called a "Thermom Graf" and manufactured by the Hallikainen Instrument Company of Berkeley, California. The bridge required for high-accuracy measurements must have great resolving power and stability. When a long lead intervenes between the probe and the bridge, it is necessary to compensate for the resistance of the lead. Moreover, when ac is used, it is necessary also to compensate for the capacitance of the leads.

Several sensitivity ranges were available; in the most sensitive. precision was $0.001^{\circ} \mathrm{C}$. The The rmo-Graf uses an arbitrary scale system of decades whose interrelation was established experimentally. Each of the probes was calibrated against the Thermo-Graf at four temperatures. This work was done at the laboratories of Hallikainen Instruments, through the courtesy of Mr. Hallikainen. A large paraffin oil bath with adequate stirring was used. The temperature standards were special expanded-scale mercuryin-glas s thermometers, calibrated against primary standards in the laboratories of the Shell Development Co. Emeryville, California, or certified by the Nation Bureau of Standards.

By the use of a three-lead circuit, the effect of the cable resistance was eliminated on the as sumption that variations in the resistances of the leads in the cable were identical. The capacitance of 1,000 feet of cable was compensated for by capacitors in the bridge circuit of the Thermo-Graf.

For less accurate measurements the resistance of the platinum the mometer could be determined to about $0.1 \%$ by using a portable dc Wheatstone bridge manufactured by Leeds and Northrup Company. Accurate measm urements (to $10.01^{\circ} \mathrm{C}$ or better) were to be determined using the ac bridge mentioned above.

\section{3.2 Field Calibrations and Operations}

Certain exigencies of field types of operations raised the need for recalibrations in the field and modification of original plan of attack. These recalibrations and changes are described in the following sections.

No further calibration was done with the ac bridge, but probe failures forced the calibration of additional equipment for use with the dc bridge. This was done in the field at the Nevada. Test Site by means of adapting a dewar flask for use as a comparator bath. A BKH \#61610 mercury thermometer, having a range $-20^{\circ}$ to $110^{\circ} \mathrm{C}$ with an error of $\pm 0.3^{\circ} \mathrm{C}$ for the entire range, was used to measure the temperature of the bath. The dewar was fitted with a 750-watt heating element and electric stirring device. A block of styrofoam insulation was added as a lid to keep thermal losses at a minimum. The bath was filled with distilled water which was heated in $15^{\circ}$ steps to approximately $90^{\circ} \mathrm{C}$. With this apparatus, it was possible to maintain the temperature of the bath to $\pm 0.1^{\circ} \mathrm{C}$ while the platinum resistance was measured. All 
probes were calibrated with 300 or 1000 feet of three-conductor copper cable attached.

The field calibrated probes when cross calibrated with the original Broadview Research probes were found to be within $\neq 0.6 \%$ of the Broadview Research results. The reliability of this field calibration varied from $\pm 0.4^{\circ}$ at $0^{\circ} \mathrm{C}$ to $\pm 0.5^{\circ}$ at $90^{\circ} \mathrm{C}$.

After the measurements were completed, a temperature bath was constructed to $x$ ecalibrate the probes. The reliability of this calibration varied from $0.26^{\circ}$ at $0^{\circ} \mathrm{C}$ to $\pm 0.38^{\circ}$ at $90^{\circ} \mathrm{C}$ and agreed, as shown in Table 2. 1 with the earlier field calibrations.

\section{TABLE 2.1 COMPARISON OF PLATINUM RESISTANCE} THERMOMETER CALIBRATIONS

\begin{tabular}{cccc}
\hline $\begin{array}{l}\text { Resistance of } \\
\text { platinum, ohms }\end{array}$ & $\begin{array}{l}\text { Temperature, }{ }^{\circ} \mathrm{C} \\
\text { field calibration }\end{array}$ & $\begin{array}{c}\text { Temperature, }{ }^{\circ} \mathrm{C} \\
\text { laboratory calibration }\end{array}$ & $\begin{array}{c}\text { Temperature } \\
\text { difference, }{ }^{\circ} \mathrm{C}\end{array}$ \\
\hline 109.37 & 22.69 & 22.58 & -0.11 \\
112.45 & 30.54 & 30.38 & -.16 \\
116.48 & 40.81 & 40.67 & -.14 \\
120.11 & 50.06 & 49.87 & -.19 \\
124.13 & 60.31 & 60.17 & -.14 \\
127.87 & 69.84 & 69.67 & -.17 \\
131.93 & 80.19 & 80.12 & -.07 \\
135.55 & 89.42 & 89.37 & -.05 \\
\hline
\end{tabular}

This bath consisted of a 5.5 gallon container of distilled water which was indirectly heated by eight 200 -watt light globes equally spaced ar ound the containe $r$ and supported within a thermally insulated box $3 \mathrm{ft}$ square. Temperature control was accomplished by inmersing in the liquid a the $\mathrm{T}$ mistor connected to one arm of an ordinary Wheatstone bridge. The resistance variation of the thermistor with temperature determined a bridge voltage output. This output was then fed to an amplifier which controlled a motor-driven rheostat in the bath heater circuit. The temperature was controlled to better than $\pm 0.07^{\circ} \mathrm{C}$ with this apparatus.

To measure the bath temperature, a Fisher \#N1135 mercury thermometer calibrated by the Bureau of Standards was used. This thermometer had a range of $-5^{\circ}$ to $101^{\circ} \mathrm{C}$ with a maximum error of $\pm 0.07^{\circ} \mathrm{C}$ over the entire range.

For diagnostic purposes, four holes were drilled into the shot area. Table 2.2 and Figs. 2.4,2.5, and 2.6 describe these holes.

Temperature measurements were made in these holes with the platinum resistance probe and the D.C. Wheatstone Bridge or the ac Resistance bridge. Referring to Fig. 2.7, resistance values for $R_{1}, R_{2}, R_{3}, R_{A B}$ and $R_{B C}$ had been determined at a reference temperature $T_{0}$ where:

$\mathbb{R}_{1}, \mathbb{R}_{2}$ and $\mathbb{R}_{3}$ were resistances of the copper conductors.

$R_{c}$ was the resistance of a manganin resistor.

$R_{P t}$ was the resistance of the platinum resistor. 
TABLE 2.2 DESCRIPTION OF LOGGING HOLES

\begin{tabular}{|c|c|c|c|c|}
\hline $\begin{array}{l}\text { Hole } \\
\text { No. }\end{array}$ & Drilling Station & $\begin{array}{l}\text { Total } \\
\text { depth, ft }\end{array}$ & $\begin{array}{l}\text { Total ft of } \\
\text { casing in hole }\end{array}$ & $\begin{array}{l}\text { Closest distance } \\
\text { from hole to } G . Z \text {. }\end{array}$ \\
\hline 1 & Mesa & $912 *$ & $897 \mathrm{NX}^{1}$ & $7 \mathrm{ft}$ above, $19 \mathrm{ft} \mathrm{N} 32^{\circ} \mathrm{W}$ \\
\hline $\mathbf{B}$ & $\begin{array}{l}\text { In tunnel, } 211.6 \mathrm{ft} \\
\text { from } G . Z\end{array}$ & 250.5 & $250.7 \mathrm{NX}$ & $56.8 \mathrm{ft}$ below, $12 \mathrm{ft}$ right \\
\hline $\mathrm{C}$ & $\begin{array}{l}\text { In tunnel, } 211.6 \mathrm{ft} \\
\text { from } \mathrm{G} . \mathrm{Z} .\end{array}$ & 284.5 & $284.5 \mathrm{NX}$ & $27.8 \mathrm{ft}$ below. 26 ft right \\
\hline$D$ & $\begin{array}{l}\text { In tunnel, } 211.6 \mathrm{ft} \\
\text { from G. } 2 .\end{array}$ & 288.5 & $\begin{array}{l}211.5 \mathrm{NX}+ \\
288.5 \mathrm{BX}^{+}\end{array}$ & $3 \mathrm{ft}$ above, $4 \mathrm{ft}$ right \\
\hline
\end{tabular}

Hole is only open to a depth of 877 ft because 35 ft of drilling rods were lodged in the bottom of the hole.

T inch i.d. $\times 1 / 4$ in. wall thickness.

† $2-3 / 4$ in. i. d. $\times 3 / 16$ in. wall thickness.

$$
\begin{aligned}
& R_{A B_{T_{0}}}=R_{c}+R_{1_{T_{0}}}+R_{2_{T_{0}}} \\
& R_{B C_{T_{0}}}=R_{P t_{T_{0}}}+R_{Z_{T_{0}}}+R_{3_{T_{0}}}
\end{aligned}
$$

The manganin resistor potted in the probe had a very low temperature coefficient of resistivity. Therefore, at the temperatures encountered $\left(0^{\circ}\right.$ to $\left.100^{\circ} \mathrm{C}\right)$ it had a constant resistance $R_{c}$. To determine $R_{P t}$ (see Fig. 2.7):

$$
\begin{aligned}
& R_{P t}=R_{B C_{T}}-\left(R_{2_{T}}+R_{3_{T}}\right) \\
& R_{P t}=R_{B C}-\left[\left(R_{Z_{T_{0}}}+R_{3_{T_{0}}}\right)+\Delta\left(R_{2}+R_{3}\right)_{T_{0}}^{T}\right] \\
& R_{P_{t}}=R_{B C_{T}}-\left[1+\frac{\Delta\left(R_{2}+R_{3}\right)_{T}^{T}}{\left(R_{2_{T_{0}}}+R_{T_{T}}\right.}\right]\left(R_{2_{T_{0}}}+R_{3_{T_{0}}}\right)
\end{aligned}
$$

Since all three copper conductors lie in the same cable and, hence, had the same temperature distribution, the percentage change of resistance from $T_{0}$ to $T$ would be equal in $R_{1}, R_{2^{2}}$ and $R_{3}$. Thus:

$$
\frac{\Delta\left(R_{2}+R_{3}\right)_{T}^{T}}{R_{Z_{T_{0}}}+R_{3_{T_{0}}}}=\frac{\Delta\left(R_{1}+R_{2}\right) T_{T_{0}}^{T}}{{ }_{1_{T_{0}}}+R_{2_{T_{0}}}}
$$


Therefore:

$$
R_{P t}=R_{B C_{T}}=\left[1+\frac{\Delta\left(R_{1}+R_{2}\right)_{T}^{T}}{\left(R_{T_{T}}+R_{2_{T}}\right)}\right]\left(R_{T_{T_{0}}}+R_{3_{T_{0}}}\right)
$$

All of the parts of the right hand side of equation (7) could be measured directly.

The ac resistance bridge was used to measure temperatures up to $25^{\circ} \mathrm{C}$. Higher temperatures could not be measured because the bridge calibration was upset by capacitance variations with temperature in the 300-foot 3-conductor cable. As seen in Fig. 2.7, the probe connects to the ac bridge such that the cable lead resistance external to the probe appears in opposite arms of the bridge. Thus, the platinum resistance may be determined by using equation (8) derived from the Broadview Research calibration.

$$
{ }^{\circ} \mathrm{C}=0.0055287 \text { (total divisions) }-19.489+\mathrm{P}_{\mathrm{C}}
$$

where $P_{\text {f }}=$ individual probe correction. The values for total division could be read Girectly from the bridge.

The platinum resistance probe was positioned in the holes using $1 / 8$. in. steel pipe that was thermally insulated from the sensing element, and the time required for the probe to reach thermal equilibrium was determined. Since it required up to one to two hours for the probes to reach equilibrium, two methods were used in making the temperature measurements. During the drilling process, 10 -minute measurements were made at the bottom of the hole as the hole was advanced and converted to equilibrium temperatures. This was done to delay the drilling as little as possible but yet obtain measurements as the hole advanced. After the holes were complete, the probe was postitioned in the holes at 5\%, 10\%, or 20-ft intervals and left at each position until equilibrium was reached.

To obtain the normal tuff temperatures, a number of holes were drilled to depths of 6 to $40 \mathrm{ft}$ in the walls of the tunnel at approximately 200-ft in tervals from the drilling room to the portal (see Fig. 2.6). The probes were sealed in these holes and measurements were made two or three times a week with the ac resistance bridge.

Measurements were also made in the vertical mesa hole with thermistors by USGS. 

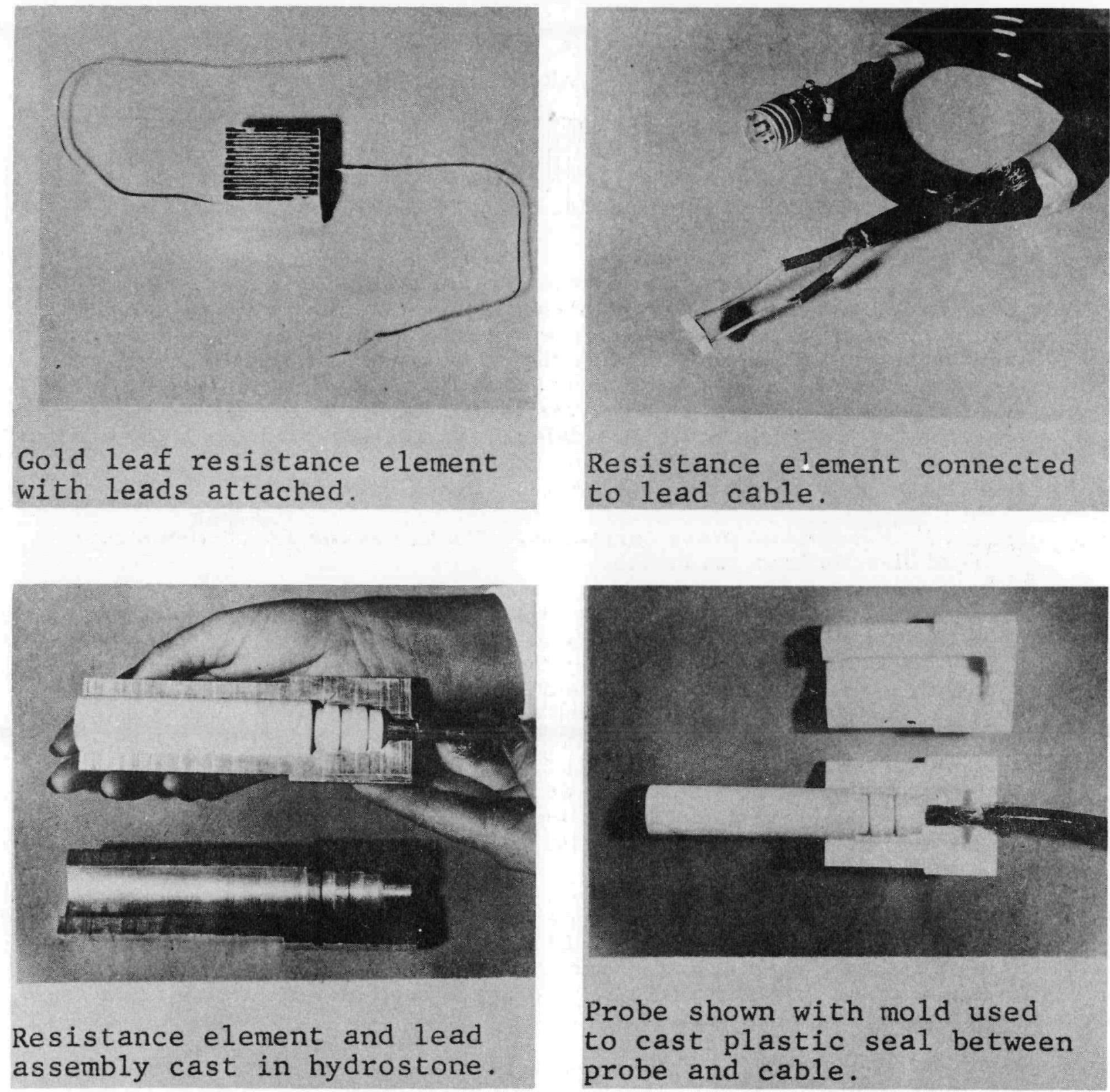

Figure 2.1 


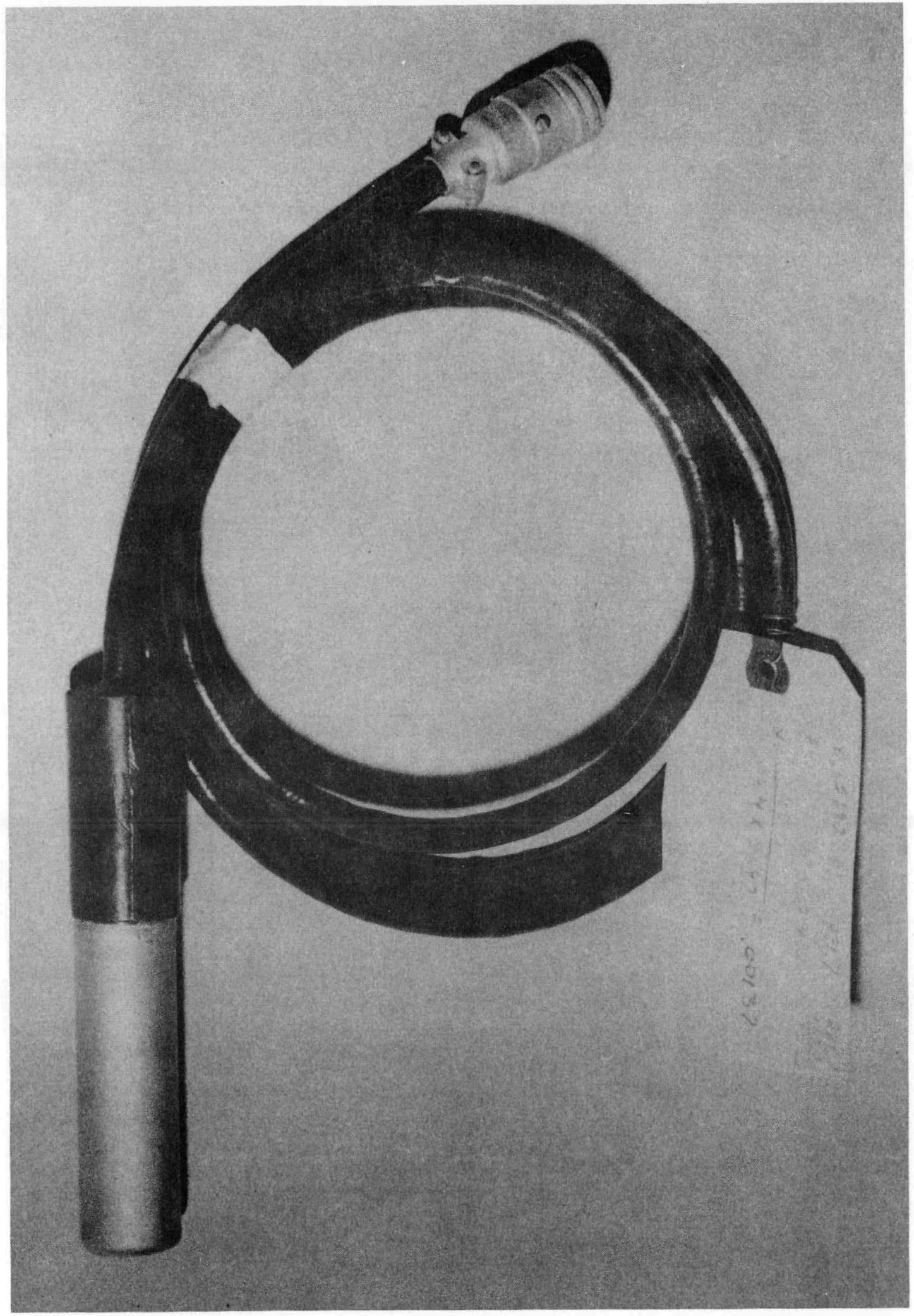

Figure 2.2 


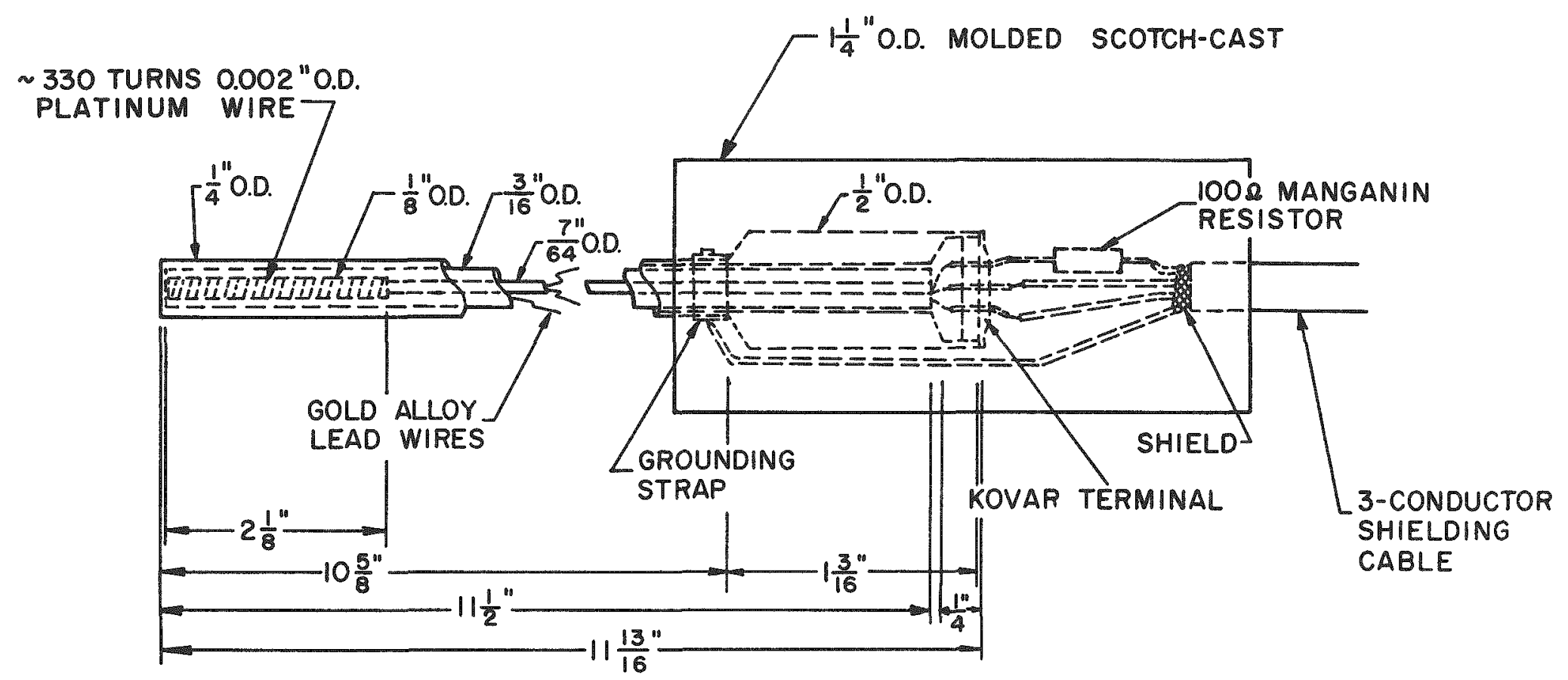

Figure 2.3 


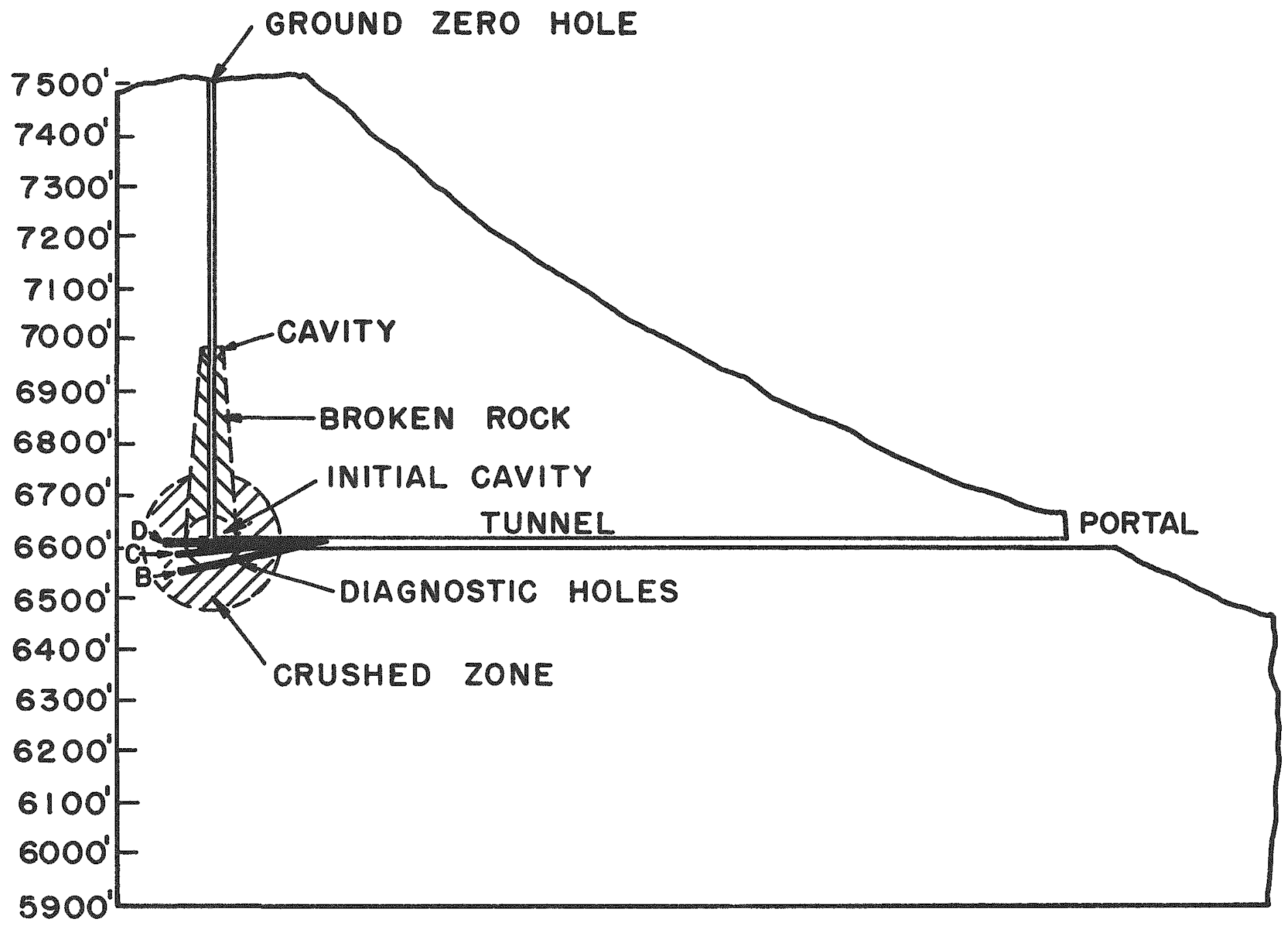

Figure 2.4 


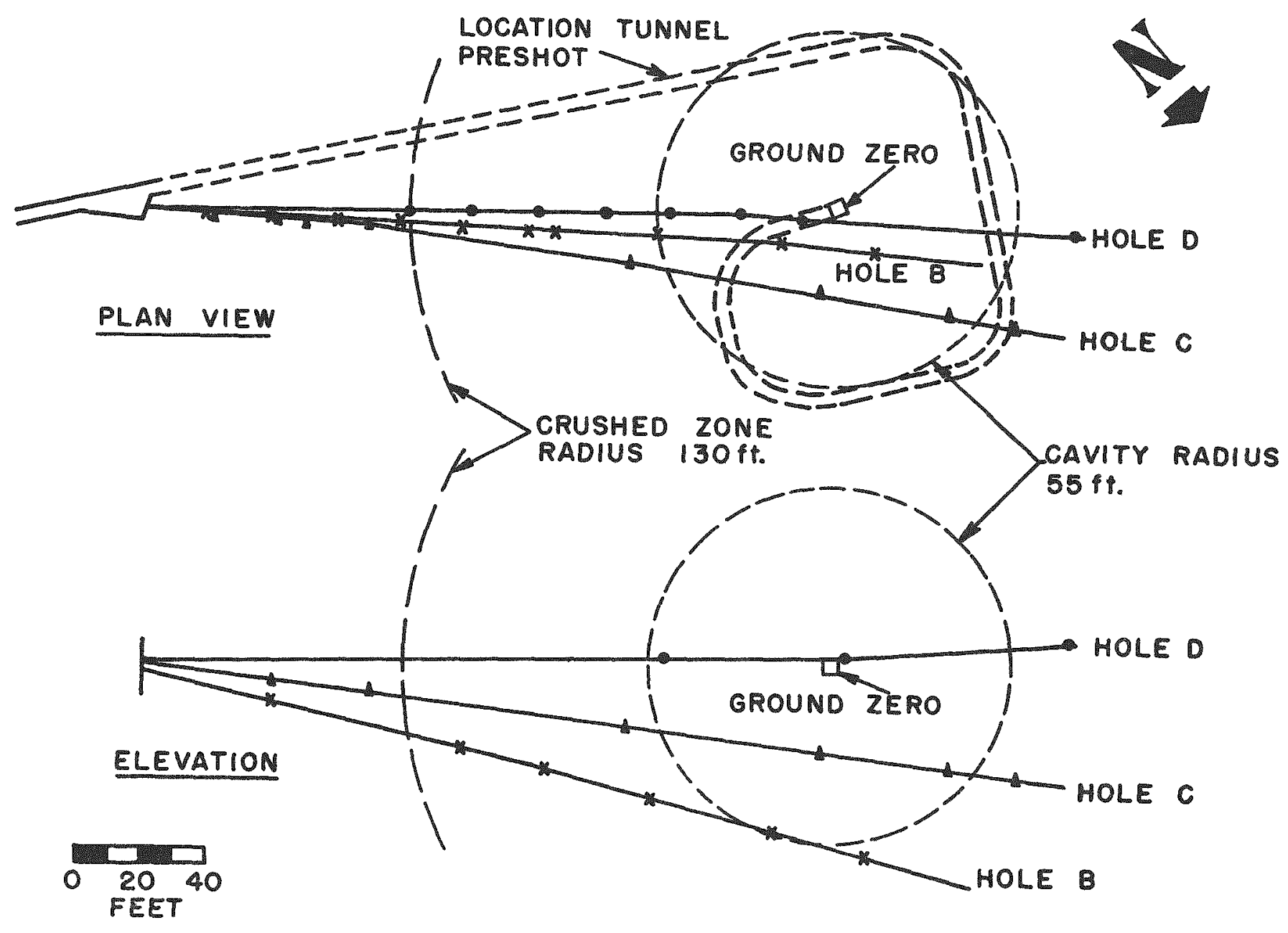

Figure 2.5 


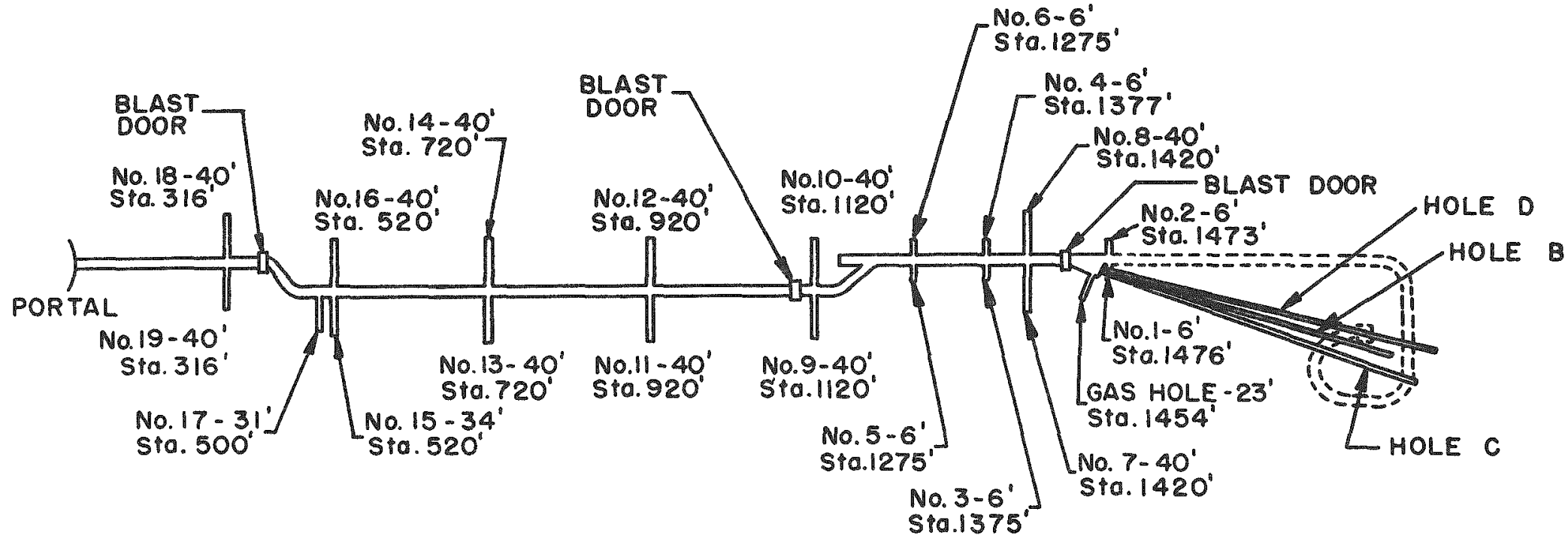

Figure 2.6 


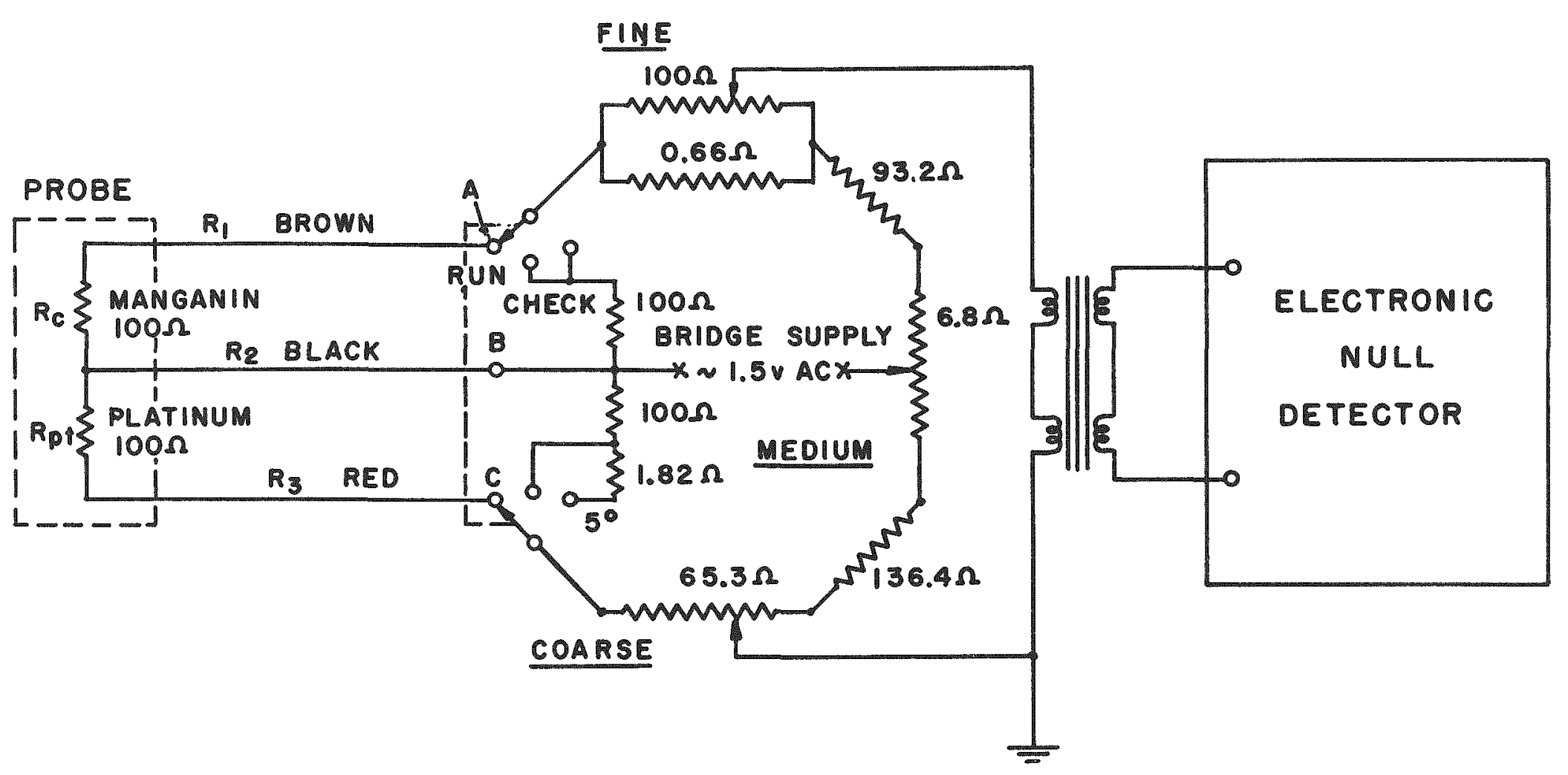

Figure 2.7 


\title{
CHAPTER 3
}

\author{
RESULTS
}

Rainier shot of Operation Plumbob was fired at 09 hours, 59 minutes, 59.45 seconds on September 19, 1957 (Reference 4). The measurements recorded during and after the detonation in the installations described in Chapter 2 are discussed in the following sections.

\subsection{PRESSURES BEHIND TUNNEL BLAST DOORS}

The shot tunnel was reentered within a few hours after detonation. The pressure gage stations at the mouth of the tunnel indicated negligible pressure rises behind each of the blast doors in the tunnels. Upon penetrating the tunnel about four hours after detonation, the blast doors were found to be satisfactorily sealed and the pressure rises behind them, as read at the local gage stations, was below the sensitivity of the gages to record. These observations together with the lack of radioactivity in the tunnel indicated that the tunnel had sealed satisfactorily, according to predictions.

\section{2 TRANSIENT TEMPERATURE RISE IN TUFF DURING PASSAGE OF SHOCK WAVE}

Five probes were installed at distances of approximately $25,45.5,95.5$, 400 , and $600 \mathrm{ft}$ from the detonation point and grouted in place with a special grout supplied by UCRL. The full-scale deflections chosen for each of these locations were $100,25,0.5,0.2$, and $0.2^{\circ} \mathrm{C}$, respectively.

The first signal which appeared on the records was essentially coincident with the detonation of the device and apparently consisted of an electrow magnetic disturbance which was initiated by the detonation. On the more sensitive ranges (the two most distant sensors) the signal was of such a magnitude that the recording apparatus shows a permanent "set" so that the signal saturated the amplifiers for a long period of time and obscured any temperature signals which might have been present. Although the existence of this spurious signal had been anticipated and the gages were as well-shielded as was felt compatible with the desired temperature measurement, the signal was large enough to completely cover and mask the desired information on these channels.

The three close-in channels $(25,45.5$, and $95.5 \mathrm{ft}$, respectively) were recovered partially after the spurious signal, but the signals which followed were not interpretable in terms of temperature. One of the reasons for this is the low-frequency response of the system which did not permit resolution of information containing frequency components higher than about 500 cycles per second. It is possible also that strain effects may have masked the desired temperature signal even though precautions to exclude these effects were taken in the design of the temperature sensors. In addition, low-frequency electromagnetic signals may have persisted long enough to cause confusion in the recorded signals. The signal recorded on one of the three close-in channels is reproduced in Fig. 3.1.

\section{3 POST-SHOT TEMPERATURE MEASUREMENTS IN THE MEDIUM SUR- ROUNDING THE NUCLEAR DETONATION}

The temperature distributions in the four diagnostic holes are shown in Figs. 3.2, 3.3 and 3.4. A plot of the isothermal lines on a surface defined by the holes $B, C$, and $D$ is shown in Fig. 3.5. The highest temperature observed was $89.7 \pm 0.4^{\circ} \mathrm{C}$. The normal tuff temperature at this depth 
is $16.6 \pm 0.1^{\circ} \mathrm{C}$. Heating from the shot occurred as far as $180 \mathrm{ft}$ from ground zero (G.Z.) in the B, C, and D holes and extends approximately $87 \mathrm{ft}$ above G.Z. in the vertical hole. This asymmetry is clearly shown in Fig. 3.5. This figure indicates that the center of the heat source is located approximately 50 ft below $G . Z$. and that the maximum temperature is less than or equal to the boiling point of water (approximately $94^{\circ} \mathrm{C}$ at shot altitude).

The exact boundary of the heated zone is difficult to determine because of the thermal perturbations introduced by the drilling operation. These perturbations include the heating of the rock by the dxill bit, the cooling by the drill water and the heat transfer in the casing in the hole. These effects are shown in Fig. 3.5 in the region below $20^{\circ} \mathrm{C}$.

Temperature measurements were made at three points in a vertical hole drilled from a point on the mesa $899 \mathrm{ft}$ above and 13.5 ft $\mathbb{N} 48^{\circ} 30^{\prime} \mathrm{W}$ of $\mathrm{G} \cdot \mathrm{Z}$. At $539 \mathrm{ft}$ the temperature measurement was $12.2 \pm 0.4^{\circ} \mathrm{C}$, at $670 \mathrm{ft}$ it was $11.7 \pm 0.4^{\circ} \mathrm{C}$ and at $685 \mathrm{ft}$ it was $10.2 \pm 0.4^{\circ} \mathrm{C}$. The temperature at $539 \mathrm{ft}$ was measured at the bottom of an inverted cone-shaped cavity $26 \mathrm{ft} \mathrm{high}$ and $50 \mathrm{ft}$ in diameter. This cavity resulted from the collapse of the initial cavity formed at $G . Z$. The $12.2 \pm 0.4{ }^{\circ} \mathrm{C}$ temperature measured at this point compares with a pre-shot temperature of $12.6 \pm 0.1^{\circ} \mathrm{C}$ recorded by USGS at the same depth in a vertical hole located $87 \mathrm{ft} \mathrm{N} 65^{\circ} 20^{\prime} \mathrm{W}$ from this post-shot hole. The results observed at $670 \mathrm{ft}$ and $685 \mathrm{ft}$ are lower than the pre-shot values obtained by USGS (Reference 5) at the same depth (Figs. 3.6 and 3.7). This is believed to be a result of the large amount of drilling water lost to the medium during the drilling process. Two temperature logs of this hole by USGS (Reference 5) 20 days apart, two months later, indicated that the temperature at these points was still below but approaching pre-shot values (see Fig. 3.7).

Duxing the post-shot drilling operation, approximately 68,000 gallons of water $\left(10^{\circ}-15^{\circ} \mathrm{C}\right)$ were lost in the vertical mesa hole between $513 \mathrm{ft}$ and 899 ft and approximately 7,000 gallons $\left(10^{\circ}-15^{\circ} \mathrm{C}\right)$ in holes $B, C$, and $D$. This is smail compared with the $3(10)^{7}$ gallons (20\% by weight) of water contained in the pre-shot tuff in the heated zone. Therefore, the gross effect in cooling the heat source is negligible. However, the effect can be seen in the boundary areas as shown in a comparison of the pre-shot and post-shot USGS measurements (Figs. 3.6 and 3.7). The water lost to the medium in drilling the $B$, $C$, and $D$ holes was lost in the region within $60 \mathrm{ft}$ of $G . Z$. This corresponds to the initial cavity formed by the shot.

The ambient rock temperature along the tunnel was measured in $6-$ and 40-ft deep horizontal holes as shown in Fig. 3.8. A temperature of 16.6 t $0.1^{\circ} \mathrm{C}$ was measured at the G.Z. depth. The temperature along the tunnel decreases as the portal is approached as shown in Fig. 3.8. The 6uft horizontal holes were not satisfactory for determining background rock temperatures because of the cooling resulting from the air circulating in the tunnel. In the 40-ft horizontal holes, a cooling of 0.05 to $0.1^{\circ} \mathrm{C}$ was observed in a pexiod of 56 days.

After the drilling was completed, two temperature logs were made in the $B$ hole 58 days apart (144 and 202 days after the shot). As seen in Fig. 3. 2, these curves have essentially the same shape. Integrating the area under the curves, however, showed that a $6.4 \%$ reduction had occurred in 58 days. The peak temperature in this period had dropped from $89.7^{\circ} \mathrm{C}$ to $84.2^{\circ} \mathrm{C}$. A similax compaxison of two temperature logs made 45 days apart (118 and 163 days after the shot) in the D hole showed a reduction of $3.2 \%$ in the area of overlap. The average rate of change in the $B$ hole is -0.11 $0.02 \%$ per day. The average rate of change in the $\mathrm{D}$ hole is $-0.07 \pm 0.02 \%$ 
per day. Figure 3.2 also shows a partial log made in the $B$ hole before casing the hole and during the drilling operation. It is difficult to interpret the comparison of this logging with that of the cased hole because not enough information is known on the effects of casing, drilling water, etc.

A tunnel is now being driven into a point approximately 20 ft vertically below G.Z. From this point, more diagnostic holes will be drilled to obtain better definition of the geometry and magnitude of the shot effects. 


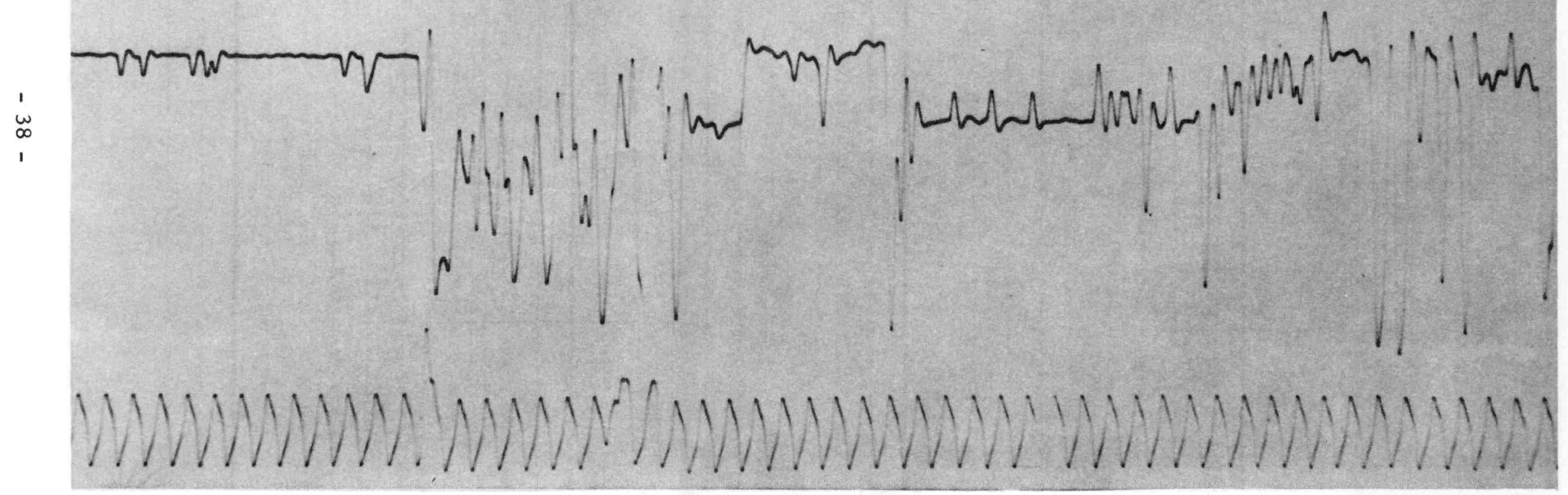

Figure 3.1 


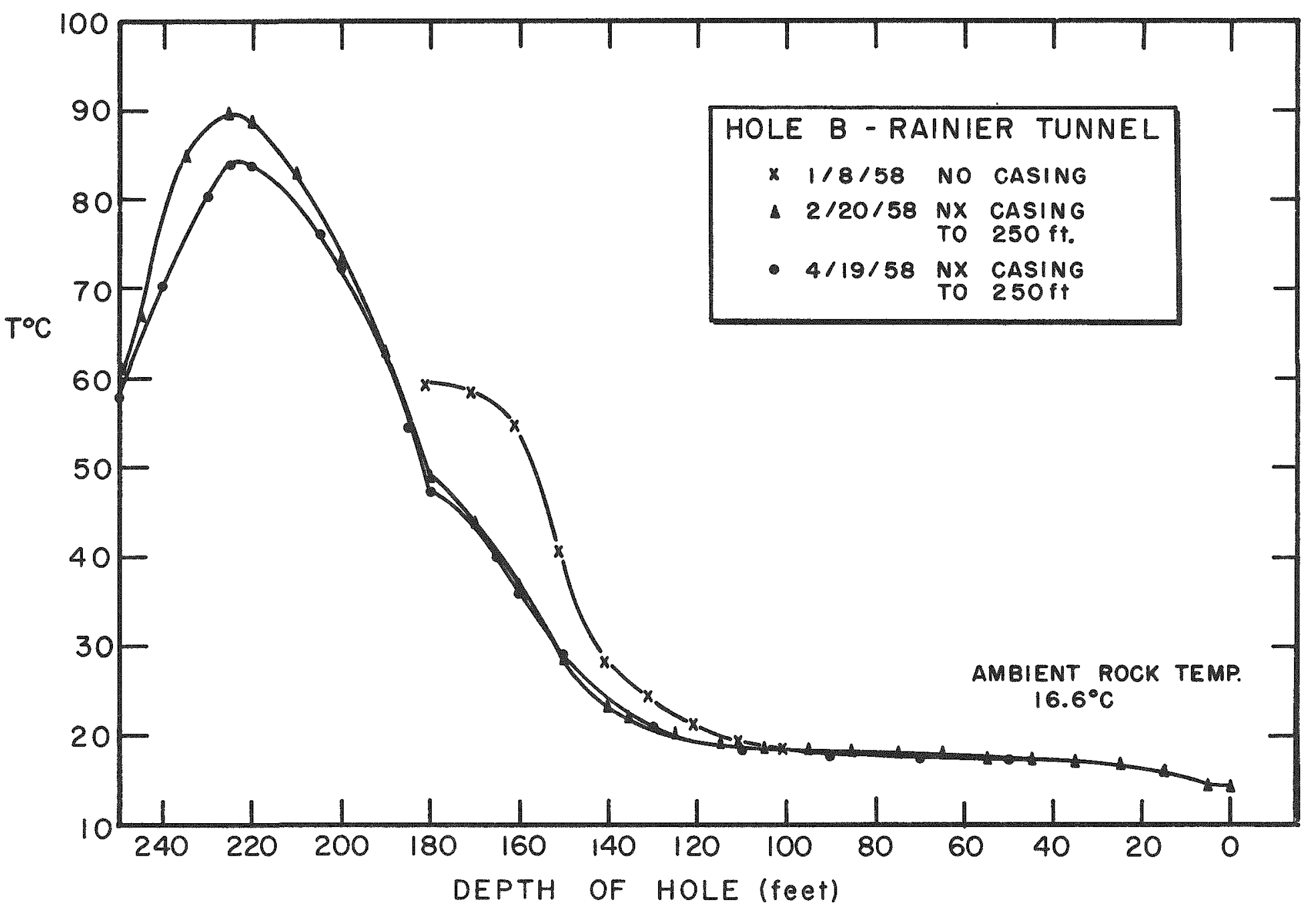

Figure 3.2 


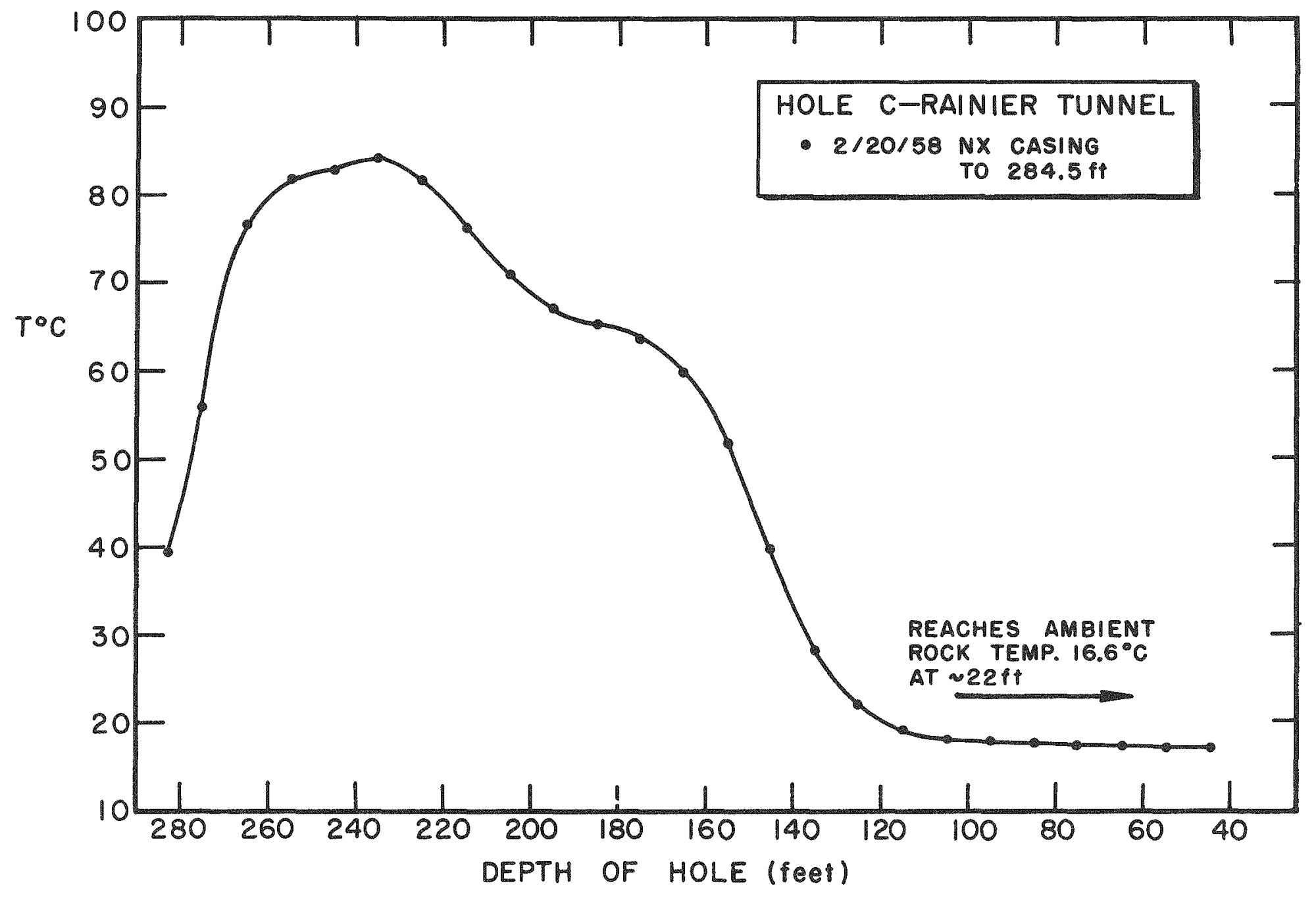

Figure 3.3 


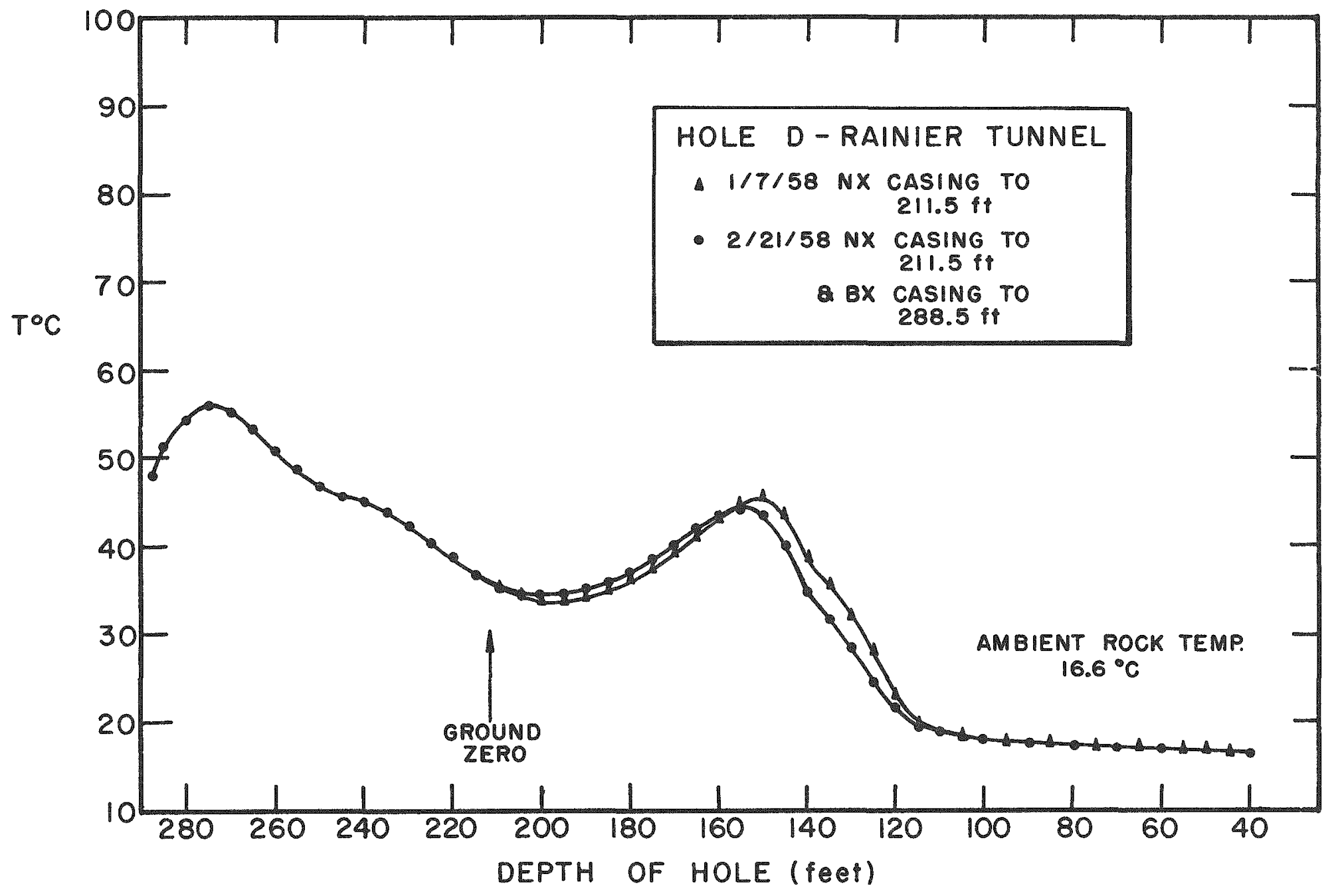

Figure 3.4 


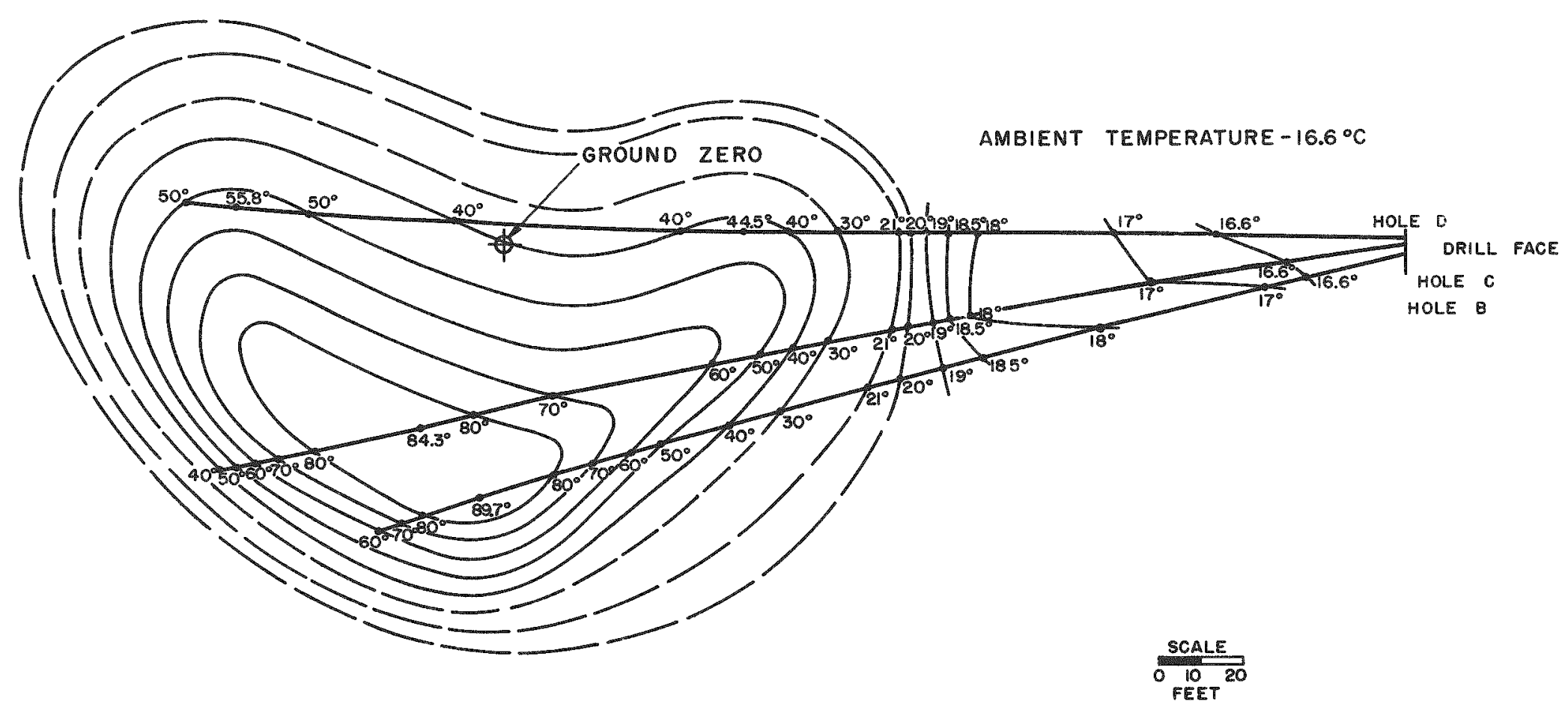

Figure 3.5 


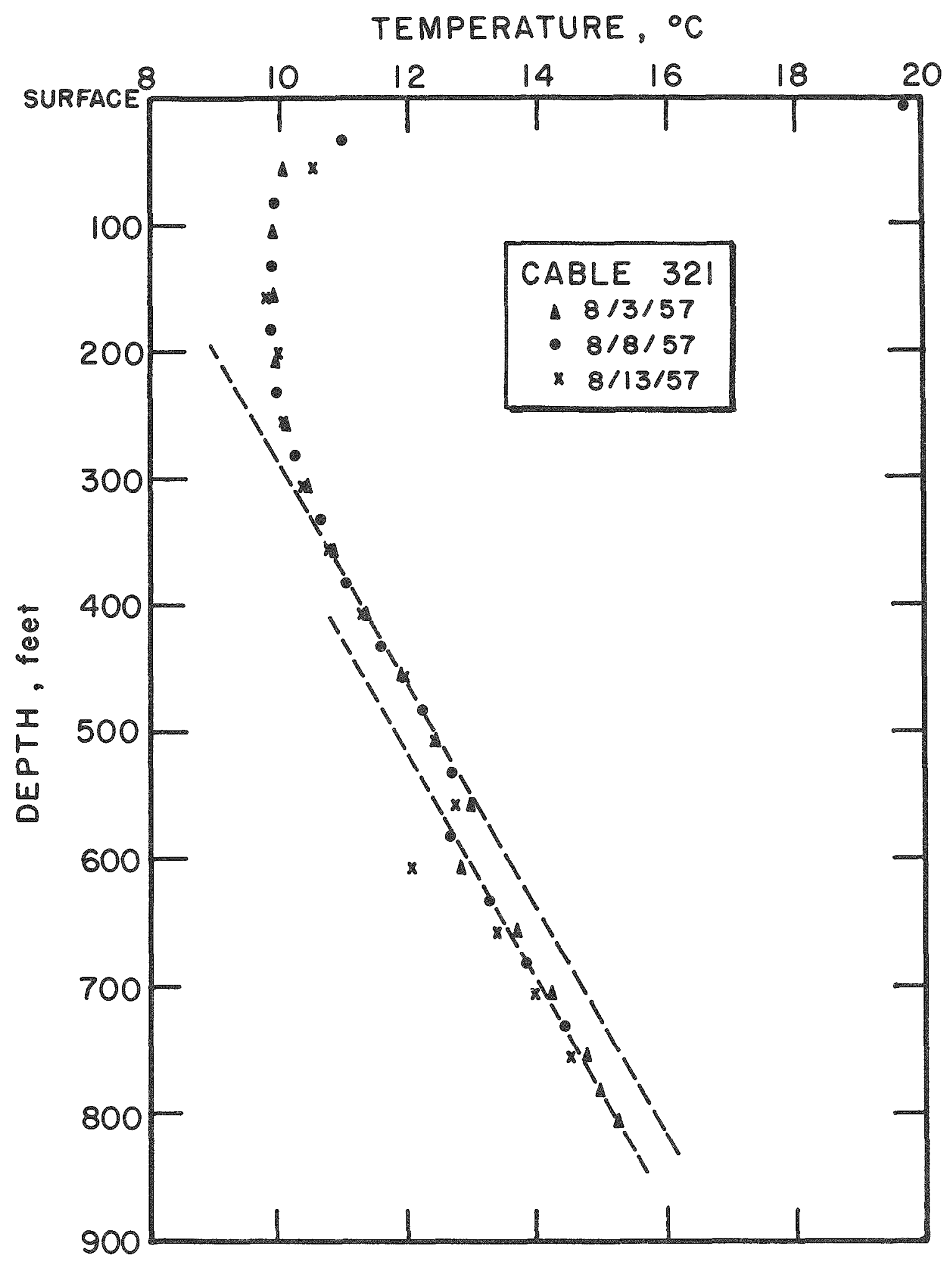

Figure 3.6 


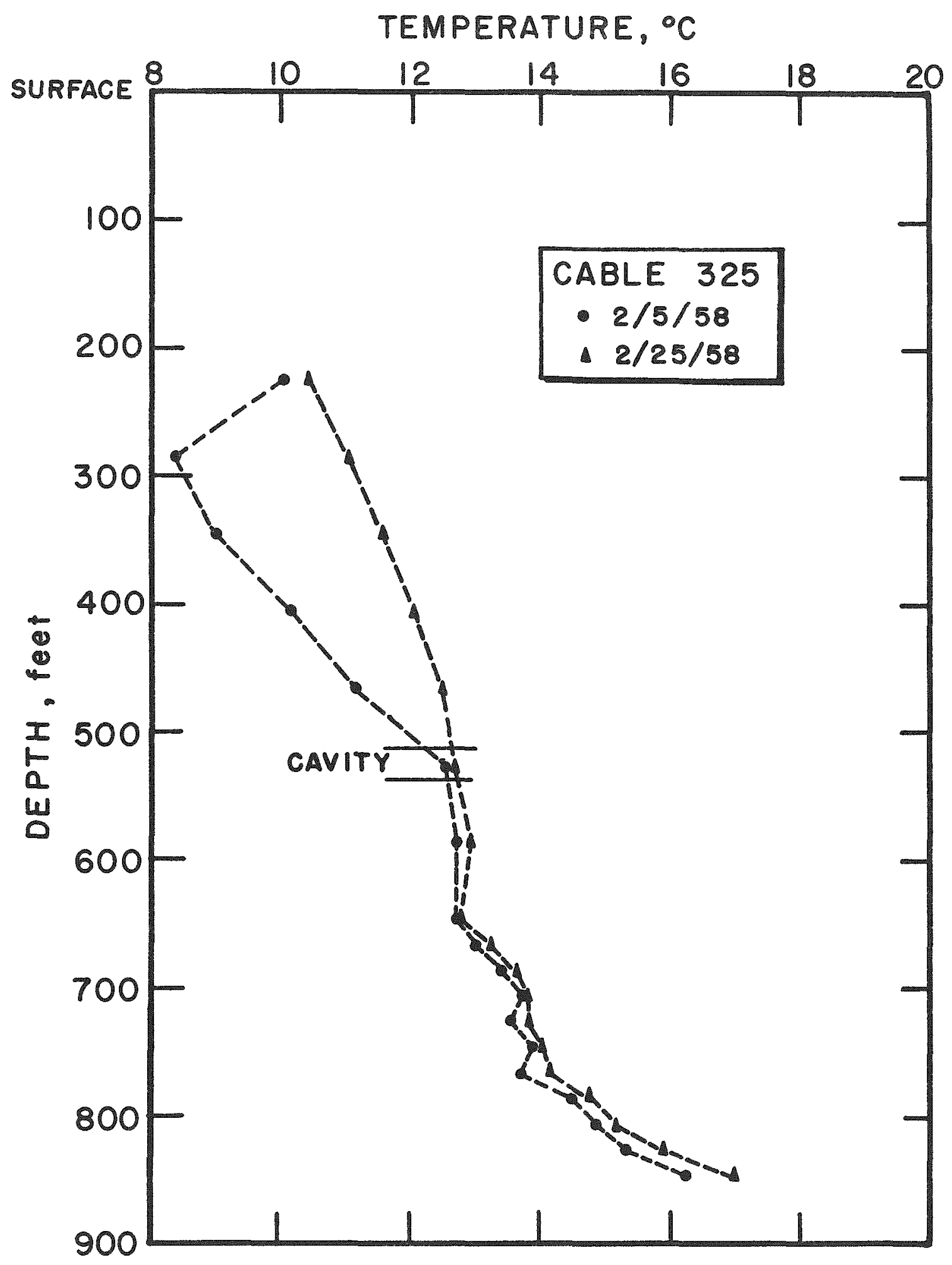

Figure 3.7 


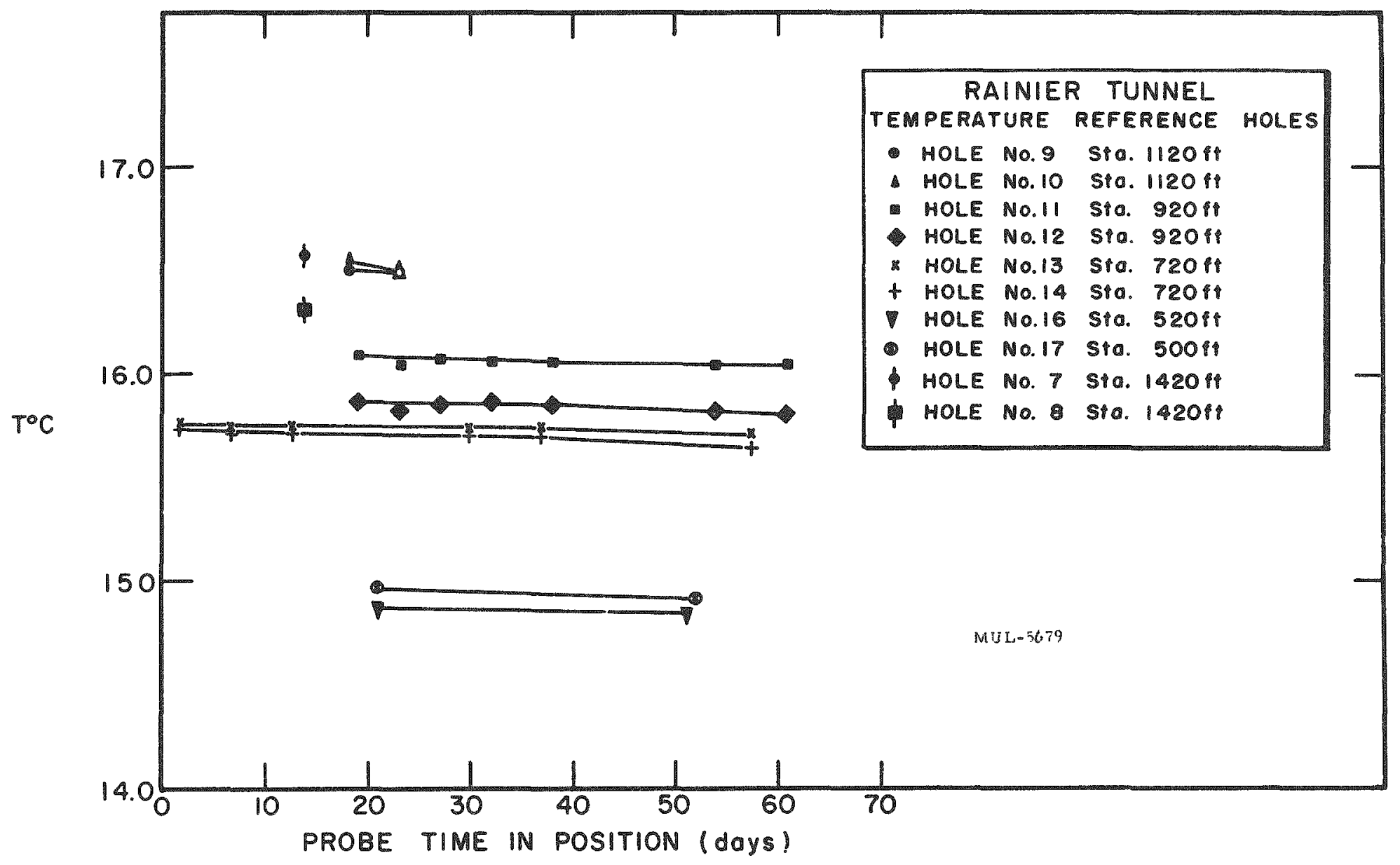

Figure 3.8 


\section{CHAPTER 4}

\section{DISCUSSIONS AND RECOMMENDATIONS}

The results of the measurements described in the previous chapters, when viewed together with results obtainable from the other experiments conducted on this shot, give a coherent picture of the sequence of events in the nuclear detonation fired deep undergrounc in Nevada tuff. The general conclusions which can be drawn from the results of the measurements described in the previous chapter are discussed below.

\subsection{EFFECTIVENESS OF TUNNEL DESIGN}

The lack of static pressure in the tunnels behind the blast doors and also the lack of damage to the blast doors indicated that the original concept of the tunnel design was effective in preventing the energy of the detonation or explosive products from venting into the tunnel.

It is recommerded that this blast-door instrumentation be inciuded in any similar type futare installations.

\section{2 TEMPERATURE RISE IN TUFF BEHIND SHOCK FRONT}

No direct results were obtained on this quantity, as discussed in Section 3.2 of Chapter 3. However, the long-term post-shot temperature measurements indicate that most of the heat energy is confined to a region les $s$ than $180 \mathrm{ft}$ in radius from the original point of detonation. This meas urement indicates that the general concept of rapid attenuation of pressure with radius and the accompanying reduction in temperature rise in the shock wave is valid. As was seen in Section 1.3 .2 no appreciable temperatura rise was anticipated for shock pressures of $10^{3}$ bars or less, corresponding to radii of less than $100 \mathrm{ft}$ from the explosion point.

The measurement should probably only be repeated when some advance in instrumentation technique renders the success of the measurement more probable.

\section{3 POST-SHOT TEMPERATURE MEASUREMENTS IN THE MEDIUM SUR- ROUNDING THE POINT OF DETONATION}

The measurements indicate that no temperatures greater than the boiling point of water at the se elevations $\left(94^{\circ} \mathrm{C}\right)$ exist anywhere in the region surrounding the detonation point. The hot material is collected in a dish-shaped region about 55 to $60 \mathrm{ft}$ below the original detonation point. Interior to and above this material is relatively unconsolidated soil and rock, whereas below the hot region is a layer of crushed and deformed tuff. The highest temperature was reached in the center of vitreous raterial, which appears to have been molten tuff (see Fig. 3.5).

A rough integration over the temperature distributions given in Fig. 3.5 may be made as follows: Assume that the temperature distributions axe roughly symmetrical about an axis passing through the original ground zero and the highest temperature region encountered. The volumes inclosed by the constant temperature contours may then be approximated by hemispheres having radii as estimated in Table 4.1. Using an average specific heat of 0.35 calories per gram, a density of 1.9 grams per cc, we calculated as in Table 4.1 that the total amount of energy contained in the tuff in the form of material heated above $20^{\circ} \mathrm{C}$ is $8.6 \times 10^{1} 1$ calories, or over half of the total bomb energy of $1.7 \times 10^{12}$ caloxies. 
TABLE 4.1 CALCULATION OF TOTAL HEAT CONTENT OF TUFF

\begin{tabular}{|c|c|c|c|c|}
\hline Temp.,${ }^{\circ} \mathrm{C}$ & Radius, $\mathrm{cm}$ & Vol. $=\frac{2 \pi r^{3}}{3}$ & ${ }^{\circ} \mathrm{C}$ rise, & $\begin{array}{c}\text { Heat content }=p V C_{p} \Delta t \\
\text { cal. }\end{array}$ \\
\hline $20^{\circ} \mathrm{C}$ & 3000 & $5.67 \times 10^{10}$ & $3.4^{\circ} \mathrm{C}$ & $12.8 \times 10^{10}$ \\
\hline $30^{\circ} \mathrm{C}$ & 2670 & 3.98 & $10.0^{\circ}$ & 26.1 \\
\hline $40^{\circ} \mathrm{C}$ & 2460 & 3.12 & $10.0^{\circ}$ & 20.8 \\
\hline $50^{\circ} \mathrm{C}$ & 2160 & 2.12 & $10.0^{\circ}$ & 14.1 \\
\hline $60^{\circ} \mathrm{C}$ & 1770 & 1.16 & $10.0^{\circ}$ & 7.7 \\
\hline $70^{\circ} \mathrm{C}$ & 1320 & 0.483 & $10.0^{\circ}$ & 3.2 \\
\hline \multirow[t]{2}{*}{$80^{\circ} \mathrm{C}$} & 1020 & 0.222 & $10.0^{\circ}$ & 1.5 \\
\hline & & & & $86.2 \times 10^{10}$ \\
\hline
\end{tabular}

An explanation for the above measurements which is consistent with all. the data is as follows:

Shortly after detonation a molten or fused shell was formed on the inside of the shot chamber. Almost simultaneously the walls of the chamber underwent hydrodynamic motion until a cavity with dimensions of 50 to 60 ft was formed. The amount of material in the fused layer may be estimated from radiochemical measurements, since essentially all of the fission fragments were trapped in the vitrified layer at the edge of the cavity. The volune of fused material (fusing temperature $1200-1500^{\circ} \mathrm{C}$ ) is estimated to be $3.5 \times 10^{8} \mathrm{~cm}^{3}$, corresponding to a shell thickness of about 4 in. at the cavity radius of $55 \mathrm{ft}$. Shortly after the detonation the roof of this cavity collapsed in such a manner that most of the roof material fell to the bottom of the cavity and the cavity filled with unconsolidated permeable material. This collapse was propagated upward until a stratum capable of supporting the stress was encountered.

The hot naterial was assumed to cool rapidly to a temperature below $100^{\circ} \mathrm{C}$ due to the admixture of unconsolidated tuff, when the cavity roof structure caved in, and by heating of the large quantity of water contained in this mass of rock as pore water or water of crystallization. The boiling point for water at this elevation is about $94^{\circ} \mathrm{C}$. Taking into account the fact that the once molten material is thus mixed essentially with a few feet of radial thickness of unconsolidated tuff, and adding a small amount of radial tuff thickness to account for material shock heated to above $94^{\circ} \mathrm{C}$, the total mass of hot tuff at a $55-\mathrm{ft}$ radius is seen to be about $10^{10} \mathrm{grams}$, containing about $2 \times 10^{9} \mathrm{~g}$ of water. To evaporate this amount of water would require $2 \times 10^{9} \times$ $[100-16+540]=1.24 \times 10^{12} \mathrm{cal}$. The total bomb energy is approximately 1. $7 \times 10^{12} \mathrm{cal}$ so that is is quite reasonable to assume that any high temperatures in the tuff were soon reduced to below the region of 90 to $100^{\circ} \mathrm{C}$. In a similar fashion, by assuming $400 \mathrm{cal} / \mathrm{g}$ as the latent heat of fusion for tuff and the estimate of $7 \times 10^{8} \mathrm{~g}$ of fused rraterial for radiochemical measurements, the amount of heat which entered the fused material is estimated as about $30 \%$ of the total bormb energy. 
The fact that the broken unconsolidated material is permeable to water tends to invalidate the procedural concept of long-term temperature measurements of heat conduction in the tuff, since heat will be transferred by water, vapor or even gas conduction and convection to regions of the tuff. For this reason very accurate $\left(0.001^{\circ} \mathrm{C}\right)$ long-term measurements of the heat diffusion by conduction away from the central source will not yield easily interpretable results and should probably be discontinued. On the other hand, it is vital to document the sequence of events in the shocked medium by moderately accurate temperature logging of drill holes made before and after the nuclear detonation.

\section{APPENDIX A}

This appendix gives the solution of the integral

$$
\begin{aligned}
\int_{0}^{a} r^{2} e^{-\left(r^{2}-r\right)^{2} / 4 s t}- & e^{-(x+r)^{2} / 4 s t} d r^{3} \\
& =\int_{0}^{a} r^{1} e^{-\left(r-r^{3}\right)^{2} / 4 s t} d r^{3}-\int_{0}^{a} r^{1} e^{-\left(r+r^{1}\right)^{2} / 4 s t} d r^{1}
\end{aligned}
$$

Let

$$
U=\frac{\left(x^{4}-x\right)^{2}}{4 s t}, \quad d u=\frac{\left(x^{4}-r \mid\right.}{2 s t} d r^{8}
$$

First integral is

$$
\begin{aligned}
\int r^{3} e^{-u} d r^{1} & =2 s t \int\left(\frac{r^{8}}{2 s t}-\frac{r}{2 s t}+\frac{r}{2 s t}\right) e^{-u} d r^{3} \\
& =2 s t \int e^{-u} d u+r \int_{0}^{a} e^{-\left(r-r^{3}\right)^{2} / 4 s t} d r^{3} \\
& =2 s t\left[e^{-r^{2} / 4 s t}-e^{\left.-(x-a)^{2} / 4 s t\right]}+r \sqrt{\pi s t} \operatorname{lerf} \frac{r}{2 \sqrt{s t}}-\operatorname{erf} \frac{r-a}{2 \sqrt{s t}}\right)
\end{aligned}
$$

Similarly, the second integral is solved by

$$
I=\frac{\left(r+r^{\prime}\right)^{2}}{4 s t}, \quad d y=\frac{r^{i}+r}{2 s t}
$$

The integral becomes $2 s t \int_{0}^{a} e^{-Y} d y-x \int_{0}^{a} e^{-\left(r+x^{8}\right)^{2} / 4 s t} d x^{\prime}$

and its solution is

$$
2 s t\left[e^{-r^{2} / 4 s t}-e^{-(r+a)^{2} / 4 s t}\right]+r \sqrt{\pi s t}\left(\operatorname{erf} \frac{r}{2 \sqrt{s t}}-\operatorname{erf} \frac{r+a}{2 \sqrt{s t}}\right)
$$

Combining the two we obtain

$$
\text { 2st }\left[e^{-(r+a)^{2} / 4 s t}-e^{-(r-a)^{2} / 4 s t}\right]-r \sqrt{\pi s t}\left(\operatorname{erf} \frac{r+a}{2 \sqrt{s t}}-\operatorname{erf} \frac{r-a}{2 \sqrt{s t}}\right)
$$




\section{REFERENCES}

1. Carslaw, H, S., and Jaeger, J. C., Conduction of Heat in Solids, 1947. Oxford University Press, London, England.

2. Cole, R. H. Underwater Explosion, 1948, Princeton University Press, Princeton, New Jersey.

3. Porzel, F. B., Study of Blast Effects in Soil, March 12, 1957, Armour Research Foundation Report No. DII9 Report No. 1, contract No. DA-44-009-ENG-3113, Armour Research Foundation of nllinois Institute of Technology, Chicago 16, Illinois.

4. Johnson, Gi W., Pelsor, G. T., Preston, R. G., and Violet, C. E., The Underground Nuclear Detonation of September 19, 1957 Rainier, University of California Radiation Laboratory Report UCRL -5124, Feb. 4, 1958

5. Lachenbruch, A. H. , Pre-Shot and Post-Shot Temperature Measurements in Deep Vertical Holes in the Rainier Shot Area at the NTS. U.S. Geological Survey, unpublished, 1958. 